Analysis of the Use of Wind Energy to Supplement the Power Needs at McMurdo Station and Amundsen-Scott South Pole Station, Antarctica

I. Baring-Gould, R. Robichaud National Renewable Energy Laboratory

Kevin McLain

Accurate Engineering
Technical Report NREL/TP-500-37504 May 2005 


\section{Analysis of the Use of Wind Energy to Supplement the Power Needs at McMurdo Station and Amundsen-Scott South Pole Station, Antarctica}

I. Baring-Gould, R. Robichaud

National Renewable Energy Laboratory

Kevin McLain

Accurate Engineering

Prepared under Task No. WER5.7202

National Renewable Energy Laboratory

1617 Cole Boulevard, Golden, Colorado 80401-3393

303-275-3000 • www.nrel.gov

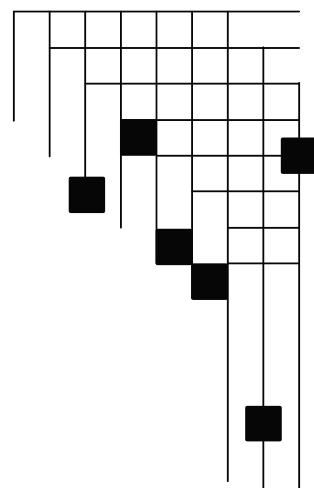




\section{NOTICE}

This report was prepared as an account of work sponsored by an agency of the United States government. Neither the United States government nor any agency thereof, nor any of their employees, makes any warranty, express or implied, or assumes any legal liability or responsibility for the accuracy, completeness, or usefulness of any information, apparatus, product, or process disclosed, or represents that its use would not infringe privately owned rights. Reference herein to any specific commercial product, process, or service by trade name, trademark, manufacturer, or otherwise does not necessarily constitute or imply its endorsement, recommendation, or favoring by the United States government or any agency thereof. The views and opinions of authors expressed herein do not necessarily state or reflect those of the United States government or any agency thereof.

Available electronically at http://www.osti.gov/bridge

Available for a processing fee to U.S. Department of Energy and its contractors, in paper, from:

U.S. Department of Energy

Office of Scientific and Technical Information

P.O. Box 62

Oak Ridge, TN 37831-0062

phone: 865.576 .8401

fax: 865.576 .5728

email: mailto:reports@adonis.osti.gov

Available for sale to the public, in paper, from:

U.S. Department of Commerce

National Technical Information Service

5285 Port Royal Road

Springfield, VA 22161

phone: 800.553.6847

fax: 703.605.6900

email: orders@ntis.fedworld.gov

online ordering: http://www.ntis.gov/ordering.htm 


\section{Contacts}

E. lan Baring-Gould

NREL

1617 Cole Blvd

Golden, CO 80401

Phone: 303-384-7021

Fax: 303-384-6901

ian_baring_gould@nrel.gov

Robi Robichaud

FEMP - NREL

1617 Cole Blvd

Golden, CO 80401

Phone: 303-384-7553

Fax: 303-384-7411

robi_robichaud@nrel.gov

Kevin McLain

Energy/Mechanical Engineer

Accurate Engineering

108 Daisy Hill Road

Lebanon, NH 03766

Phone: 603-448-2254

McLain55@verizon.net

Anne Crawley

U.S. DOE FEMP Headquarters

EE-2L 1000 Independence Ave., SW

Washington, DC 20585-0121

Phone: 202-586-1505

anne.crawley@ee.doe.gov

Randy Jones

U.S. DOE Denver Regional Office

1617 Cole Blvd

Golden, CO 80401

Phone: 303-275-4814

Fax: 303-275-4830

randy.jones@ee.doe.gov 


\section{Executive Summary}

This report summarizes an analysis of the inclusion of wind-driven power generation technology into the existing diesel power plants at two U.S. Antarctic research stations, McMurdo and Amundsen-Scott South Pole Station. Staff at the U.S. Department of Energy's National Renewable Energy Laboratory (NREL) conducted the analysis. Raytheon Polar Services, which currently holds the private sector support contract for the two research stations, was a major contributor to this report. Wind energy potential was not analyzed for Palmer Station or the various U.S. Antarctic field camps.

To conduct the analysis, available data were obtained on the wind resources, power plant conditions, load, and component cost. Whenever possible, we validated the information. We then used NREL's Hybrid2 power system modeling software to analyze the potential and cost of using wind turbine generators at the two aforementioned facilities. Unfortunately, the power systems and energy allocations at McMurdo and South Pole Station are being redeveloped, so it is not possible to validate future fuel use. Additionally, a new primary community/science facility at South Pole Station is under construction; thus only estimates of its expected power consumption are available. This report is an initial assessment of the potential use of wind energy and should be followed by further, more detailed analysis if this option is to be considered further.

\section{McMurdo Station}

We began wind speed measurement programs in late January 2003 at Twin Craters (NASA Dome Area), Crater Hill, and the Snow Dump, potential locations in close proximity to McMurdo Station. We experienced numerous anemometer failures (mainly broken cups) because of the harsh environment, but analysis of more than 6 months of reliable data from the three sites indicated that Twin Craters (near the explosives yard) has the most favorable wind speeds and persistence for wind-generating equipment. This area also has suitable road access for wind farm construction and maintenance. Because of the relatively small area available for towers at Twin Craters and the limited lift capacity of the existing crane a small number of different medium sized wind turbines were considered in the analysis.

Results indicated that capturing wind energy at McMurdo could reduce the total cost of generating power by between half a cent and 2 cents for each kilowatt-hour ( $\mathrm{kWh}$ ) produced by the power plant and reduce total fuel consumption by between 158,000 and 317,000 gallons/year (600,000 to 1,200,000 liters/year). Total net present savings for the use of wind, including all costs associated with the wind system installation, would be between $\$ 1$ million and $\$ 4$ million over a 20 -year project life. The cost of the project was modeled to be between $\$ 2$ million and $\$ 3$ million.

\section{Amundsen-Scott South Pole Station}

The analysis for South Pole Station was conducted differently because of the limited availability of wind turbines that are suited for the extreme cold at the South Pole. The 
only existing large-scale wind turbine that fulfils the temperature requirements is Northern Power Systems' NorthWind 100 model, and it will require some development and retrofit work to allow reliable, long-term operation at the South Pole.

The analysis consisted of determining the cost savings based on installing between one and 10 NorthWind $100-\mathrm{kW}$ turbines at the South Pole. Based on wind speed data collected at the South Pole metrological station, it appears that significant cost savings can be achieved by using wind energy. Although the wind speeds measured at the site are considered low, the avoided cost of fuel is so high that the installation of nine $100-\mathrm{kW}$ wind turbines would result in a net savings of almost $\$ 18$ million over a 20 -year project life. Annual fuel consumption would be reduced by almost $23 \%$, or 116,500 gallons (440,783 liters). The cost of installing nine turbines at the South Pole is expected to be approximately $\$ 4.3$ million. Further analysis could be conducted to consider a heavier reliance on wind technology but as an initial stage 10 turbines was considered appropriate.

\section{Conclusion}

This initial analysis indicates that a large potential savings could be realized by incorporating wind energy into the existing diesel plants at the South Pole Station. The economic impact of using wind power at McMurdo is not as extreme, but it is cost effective and would significantly reduce diesel fuel consumption. Given the amount of wind energy that could be included in the systems at McMurdo and South Pole Station, the current diesel plants will continue to operate, at least initially, as they currently are. Any savings will result from a reduction in fuel consumption and subsequent reduced fuel storage requirements.

Both of these analyses are based on data that are generally out of date or limited in nature; thus the results should be considered preliminary. However, even with the limitations of the data used in the analysis, the increasing electric demand (which leads to increased fuel storage and transportation needs) and the growing cost of diesel fuel will only make wind more financially attractive in any further analysis.

To advance the assessment of these opportunities, several steps should be taken at the McMurdo and South Pole stations. These include obtaining better load and power system data following a detailed energy audit of each station; more advanced wind measurement at McMurdo and initiating a wind site-specific measurement program at South Pole. Additionally, further analysis is required to quantify the impact of reducing the available 'waste' heat from the generators due to the reduction of diesel generator electrical output.

Based on the results of this analysis, there is clear potential to use wind energy to reduce the power generation costs, harmful air emissions, and fuel needs at both stations. The next step would be to conduct more detailed assessment of potential options, turbines, and systems specifications. 


\section{Abstract}

This report describes the analysis and investigation of wind energy's potential to reduce the quantity of diesel fuel consumed to provide power and heat to the two U.S. Antarctica facilities at McMurdo and the Amundsen-Scott South Pole Station. Staff from the National Renewable Energy Laboratory prepared this report with significant support from Raytheon Polar Services.

The analysis examined wind and load data from both stations and provides an initial estimate of the options for retrofitting these systems. The report also describes the next steps in the development of this project. 


\section{Table of Contents}

Executive Summary $\quad$ iv

McMurdo Station

Amundsen-Scott South Pole Station iv

Conclusion $\quad \mathrm{V}$

Abstract vi

Table of Contents vii

Table of Figures viii

Table of Tables viii

Introduction 1

McMurdo Station $\quad 2$

Existing Conditions $\quad 2$

Potential Wind Turbine Sites 2

Energy Consumption $\quad 3$

Diesel Power Plant $\quad 3$

Shipping Information $\quad 4$

Analysis of McMurdo Wind Power Options 4

Turbines Used in the Analysis 4

Wind Data $\quad 5$

Load Data $\quad 9$

$\begin{array}{lr}\text { Diesel Plant } & 10\end{array}$

Retrofitting Constraints $\quad 10$

Results of McMurdo Station Options Analysis $\quad 11$

Further Data Needed to Refine the McMurdo Analysis 14

$\begin{array}{ll}\text { Load } & 14\end{array}$

Diesel Plant 14

Wind Data 14

Constraints 14

Amundsen-Scott South Pole Station $\quad 15$

Existing Conditions $\quad 15$

Wind Speed Data 15

Energy Consumption 16

Diesel Power Plant 16

Local Information 16

Analysis of South Pole Station Wind Power Options 16

Turbines Used in the Analysis $\quad 17$

Wind Data $\quad 17$

$\begin{array}{ll}\text { Load Data } & 17\end{array}$

$\begin{array}{lr}\text { Temperature Data } & 18\end{array}$

$\begin{array}{ll}\text { Diesel Plant } & 19\end{array}$

Results of South Pole Station Options Analysis 19

Further Data Needed to Refine the South Pole Station Analysis 22

$\begin{array}{ll}\text { Load } & 22\end{array}$

Diesel Plant $\quad 22$

Wind Data $\quad 22$ 
$\begin{array}{ll}\text { Constraints } & 22\end{array}$

Conclusion $\quad 23$

References $\quad 24$

Appendix A: Primer on Diesel Retrofit Opportunities 25

Resize Diesel Generators $\quad 25$

Apply Advanced Diesel Control 25

Install Batteries and a Power Converter to Cover Low-Load Periods 25

Install Renewable Technology to Reduce Diesel Operation 26

Wind/Diesel Applications $\quad 26$

Renewable Penetration $\quad 27$

Wind/Diesel Power System Configurations $\quad 28$

Appendix References 33

\section{Table of Figures}

Figure 1. Wind speed data from Twin Craters (2003) and historical wind speed data from

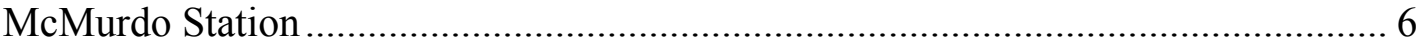

Figure 2: Wind speed data used in the analysis for McMurdo Station............................ 8

Figure 3: Historical load data for McMurdo Station .................................................... 9

Figure 4: Load data used in the McMurdo Station analysis .......................................... 10

Figure 5: Twin Craters overlooking the McMurdo Station ............................................ 11

Figure 6: Wind speed measurements taken at the South Pole metrological station for 2003

Figure 7: Energy output of the new South Pole Station diesel plant from October 1, 2001

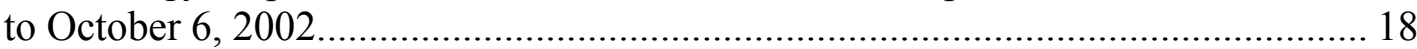

Figure 8: Temperature measurements taken at the South Pole metrological station for

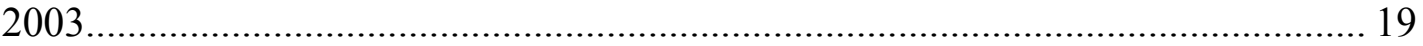

Figure 9: Results of the wind energy use analysis at the South Pole Station ................. 20

Figure A.1: Schematic of low-penetration wind/diesel hybrid ..................................... 29

Figure A.2: Schematic of high-penetration wind/diesel power system using a rotary

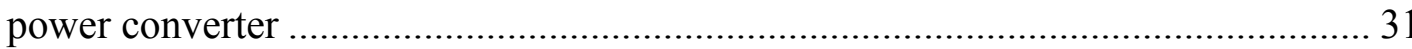

\section{Table of Tables}

Table 1: Various Wind Turbines Considered in Analysis .............................................. 5

Table 2: Summary of Collected 20-m Wind Speed Data from Three McMurdo Station

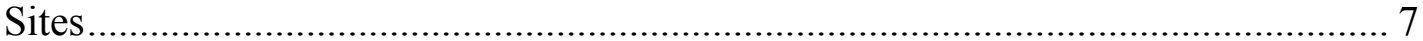

Table 3: Performance Impact of Using Wind Energy at McMurdo Station .................... 12

Table 4: Economic Impact of Using Wind Energy at McMurdo Station ........................ 13

Table 5: Economic Impact of Using Wind Energy at South Pole Station ....................... 21

Table A.1: Penetration Class of Wind-Diesel Systems (Proposed by Steve Drouilhet)... 28 


\section{Introduction}

The initial investigation of the use of large-scale renewable technologies to support the power needs of the two major U.S. Antarctic research stations, McMurdo and the South Pole, began in 1999 with a visit of staff from the National Renewable Energy Laboratory (NREL). During this visit, it was determined that one of the main applications of renewable power would be the retooling of the diesel power plants that supply electric and thermal energy to these facilities.

Three basic areas of improvement were identified:

1) Use of thermal energy from the diesel plant for heating and process needs

2) Application of energy-efficient technologies throughout the stations

3) Use of renewable energy technologies to reduce diesel-produced power.

Raytheon Polar Services has aggressively pursued improvements for areas 1 and 2, while NREL has considered the application of renewable power technologies.

Because of the current high cost of photovoltaic power and the seasonal availability of sunshine, wind energy was considered the most feasible option for renewable power generation, especially given the significant size of the stations' power needs. The use of solar thermal building technologies and photovoltaics for small remote loads are viable options to supply energy needs in Antarctica, but they are not addressed in this report.

During a follow-up visit to the Antarctic facilities in 2002, several wind-monitoring sites were identified at McMurdo, and other data were collected from McMurdo and South Pole. In early 2003, monitoring stations were installed at three potential wind-generating sites at McMurdo, which has allowed the true assessment of the retrofitting potential at this station. Such measurement stations have not been installed at the South Pole.

The resulting analysis described in this report examines wind and load data from both stations, shows a comparative analysis of various wind-diesel power system combinations, provides an initial estimate of available options for retrofitting these power systems, and produces an initial economic assessment of these options. The comparative and financial analysis was primarily conducted using the Hybrid 2 software (BaringGould, Hybrid2), which was developed by the University of Massachusetts and NREL. This tool provides a method to analyze the performance of different wind diesel power system combinations and produces an initial economic assessment of these options.

This report summarizes the current conditions and describes the data used in the analysis and the results of the analysis for each station. At the end of each section is a list of data requirements needed for further analysis. A primer on wind-diesel power system technology is also provided in the appendix of this document.

Most of the information contained from this report was obtained by personal communication and experience of the authors, specifically with Peter Somers at Raytheon 
Polar Services. Additional information was obtained from unpublished reports: John Rand's Considerations of Renewable Energy Resources for the South Pole and several field reports filed by Ed Cannon following survey trips to McMurdo and the South Pole Station. Cost information for different turbine technologies was also obtained as part of similar wind diesel system assessments being carried out for communities in Alaska.

\section{McMurdo Station}

\section{Existing Conditions}

McMurdo is located on a volcanic island about 20 miles from the mainland of Antarctica and 2400 miles due south from New Zealand. The town site (population 1000+) sits on a southwest-facing beach area at the foot of several large hills, including Arrival Heights/Twin Craters and Crater Hill. The station consists of many buildings and is more similar to a small town than a field station. The buildings, of many different construction styles and ages, are maintained to provide the primary hub of research facilities, housing, and services to all U.S. (and some international) activities in Antarctica. The site has a seasonally active harbor where supply and fuel vessels can dock and unload cargo after a channel is created by an icebreaker. Power requirements for the stations infrastructure, laboratories, and science experiments are quite large -16,000 megawatts (MW)/year-, and reliable, high-quality power is essential.

\section{Potential Wind Turbine Sites}

Data were initially collected in mid-January 2003 at three sites in the area of the McMurdo facility: Snow Dump, situated in "The Gap" near Scott Base; Twin Craters, a location immediately above and a little to the north of the McMurdo station; and Crater Hill, which is to the northeast of McMurdo station. The Snow Dump and Twin Craters sites are accessible by road, but Crater Hill currently does not have road access. Twentymeter towers were installed at each site and outfitted with NRG Systems data-logging equipment to record wind speed and direction information. Wind data collected at McMurdo's main facilities and at a nearby NASA radar site were not considered reliable or appropriate for wind power assessment.

High winds and extreme temperatures have caused problems with the reliability of the anemometers. Therefore, a clear and long-term description of the wind speeds at the sites is not available.

Based on these data, for the periods of concurrent measurements, the Twin Craters site has a better wind resource than either Crater Hill or the Snow Dump site. Because uninterrupted data are not available for the whole year, it is unclear if this is always the case, especially during the months of high and low wind velocity: May and January, respectively. Beyond the incomplete wind assessment, however, Twin Craters is accessible by road and is located only about 0.5 miles from a $4160-\mathrm{V}$ transmission line, making it a strong preliminary first choice for wind tower placement. Further analysis considering other siting issues, such as the impact on scientific research, historic preservation, and environmental impact, will also have to be addressed. 


\section{Energy Consumption}

Two types of loads are described for the McMurdo station: electric and thermal. The electric loads provide all electrical needs and a good amount of electrically based heating. Electrical-load data from December 2001 through March 2003 were obtained from the plant. For the full year of 2002, the electrical consumption for McMurdo was 15,823 megawatt-hours (MWh).

Presently, heat is removed from the diesel generator's engine jacket coolant loop and is used to heat specified buildings, with an expected JP-5 fuel oil savings of 470,000 gallons/year (1,779,000 liters/year). Furthermore, with an upcoming redesign of the diesel power plant, additional waste heat will be available from the exhaust stacks to preheat ocean water for the reverse osmosis desalination equipment and for heating other appropriate buildings at McMurdo. However, this thermal energy usage is not tabulated and thus was hard to determine as part of the analysis.

\section{Diesel Power Plant}

The diesel power plant is currently being redeveloped to replace outdated diesel generating and control systems and technology. The new diesel plant will be made up of six Caterpillar diesel generator sets: four model 3516B for base load and two model 3512B to satisfy peaking demands.

The soon-to-be-renovated power plant consumes approximately 1,300,000 gallons/year $(4,921,000$ liters/year) with an average efficiency of approximately $11.5 \mathrm{kWh} /$ gallons $(3.04 \mathrm{kWh} /$ liter $)$ in 1999 . Cost of delivered fuel used in the analysis was $\$ 1.30 /$ gallon (0.343/liter), which represents the cost in 1999. Costs in late 2003 were $\$ 1.48 /$ gallon (0.390/liters) and increased to $\$ 1.71 /$ gallon for 2005 . This results in a 1999 cost of 11.3 cents $/ \mathrm{kWh}$ for fuel alone. The cost of diesel generator operation (maintenance, lubrication oil, equipment overhaul including labor) is approximately $\$ 15 /$ hour, which in most cases would add an additional 2 to 3 cents per $\mathrm{kWh}$ produced. This savings, however, is only achieved if the diesel engine can be shut off completely and thus does not impact the economics in this analysis.

The diesels also support thermal loops running from the jacket and engine exhaust that is used for space or water heating. Of the total caloric energy of the diesel fuel, energy output from the diesel generators is expected to be divided as follows:

- $31 \%$ to useful electric power

- $30 \%$ is consumed by the jacket (part of which is used to heat buildings through a glycol loop)

- $39 \%$ is lost in the exhaust, although plans are underway to recapture some of this energy as well.

Because the engines' residual heat is used extensively, any system modeling that reduces the heat generation from the diesel engines must include the economic impact of this loss, either by generating more energy through renewable technology or through the burning 
of more heating oil. At the time of this analysis, the impact of this loss of heating has not been taken into account, although its impact will not be too great.

\section{Shipping Information}

In 1999 , the estimated cost of shipping equipment to McMurdo was $\$ 1.4 / 1 \mathrm{~b}(\$ 3.09 / \mathrm{kg})$ by air and $\$ 0.17 / \mathrm{lb}(\$ 0.37 \mathrm{~kg})$ by ship.

\section{Analysis of McMurdo Wind Power Options}

This section describes the data used in the analysis for McMurdo Station, as well as the assumptions regarding installation and the operation of the diesel power station. This initial analysis primarily examines the amount of wind energy that could easily be absorbed into the diesel grid at McMurdo station. The report also describes wind energy equipment options and further information that is needed to allow refinement of the analysis.

Three types of data are important for the analysis of wind co-powering options. The first relates to the technology that can be used to provide power at each of the sites, the second is the energy consumption at each site, and the third is the available wind resource. These data must then be analyzed based on an understanding of the current plant structure and other limitations that each site may present.

\section{Turbines Used in the Analysis}

Turbines analyzed for use at McMurdo were selected primarily to reflect different size categories or classifications, not to represent specific turbines or manufacturers. A sample of possible turbines is provided in Table 1, although other options are certainly available. Although there are differences between specific turbines, at this level, issues of basic cost, generation capacity, weight, and size are most critical. Once a turbine class is selected, further analysis will be required to determine which turbine manufacturer and model may be the most appropriate.

A number of horizontal-axis wind turbines may be appropriate for use at McMurdo station. Turbines most used in arctic environments include units from Bonus Wind Systems and ENERCON. Three ENERCON wind turbines were used with success to repower Australia's Mawson Research Station on the Antarctic coast south of Australia. U.S. patent issues may eliminate the possibility of using ENERCON wind turbines in any U.S. project, but more research is needed on this issue. 
Table 1: Various Wind Turbines Considered in Analysis

\begin{tabular}{|lcccc|}
\hline \multicolumn{1}{|c}{ Company } & Country & Turbine & $\begin{array}{c}\text { Power } \\
\text { (kW) }\end{array}$ & $\begin{array}{c}\text { Temperature } \\
\text { Rating }\end{array}$ \\
\hline Entegrity Wind Systems Inc. & Canada/USA & EW15 & 50 & -40 \\
Lagerwey Windturbines & Netherlands & $18 / 80$ & 80 & -35 \\
Northern Power Systems & USA & NW100/19 & 100 & -50 \\
Vergnet WE Development & France & GEV 26/220 & 220 & Not Available \\
Fuhrlander Wind Turbines & Germany & FL 250 & 250 & Not Available \\
ENERCON GmbH & Germany & E-30 & 300 & -35 \\
\hline
\end{tabular}

At this point in the analysis, two wind turbines were considered for McMurdo: the Northern Power Northwind 100/19 (the standard form of the 100-kW Northwind turbine) and the Furlander FL 250, a standard 250-kW wind turbine. The Northern Power wind turbine represents a smaller, more rugged "specialty" turbine, while the Furlander represents a larger mainstream turbine. These two turbines were chosen to represent different classes of turbine choices and NREL makes no recommendation on either turbine choice. If the project were to move forward, different wind turbine companies would be contacted to provide specific information regarding the technical specification and availability of turbines for McMurdo.

The McMurdo analysis examined the installation of a number of different wind turbines to be directly connected into the diesel grid of the station. As described previously, the site at Twin Craters was selected as the most likely location for the installation of the turbines.

\section{Wind Data}

The wind data set that was used for the analysis was created using data collected from the three wind measurement locations. Historical wind speed data from McMurdo were used to evaluate long-term trends compared to the data recorded at the site. It should be noted that the historical wind speed data are from a location down in the community and were not used to predict wind speed, just to verify seasonal variation. A summary of the data collected through April 2004 is provided in Table 2, and data for Twin Craters are summarized in Figure 1. More data have been collected at Twin Craters since April but were not used in this analysis.

To the extent possible, all recorded data from the measurement sites were used in the creation of the wind data file used in the analysis. The wind data for Twin Craters is not continuous and does not cover an entire year, indicating that more data collection is 
needed. However, for the purposes of an initial scoping and recommendation report, stitching together various wind data reports from nearby sites has provided a rough (but reasonable) estimate of wind profiles and characteristics.

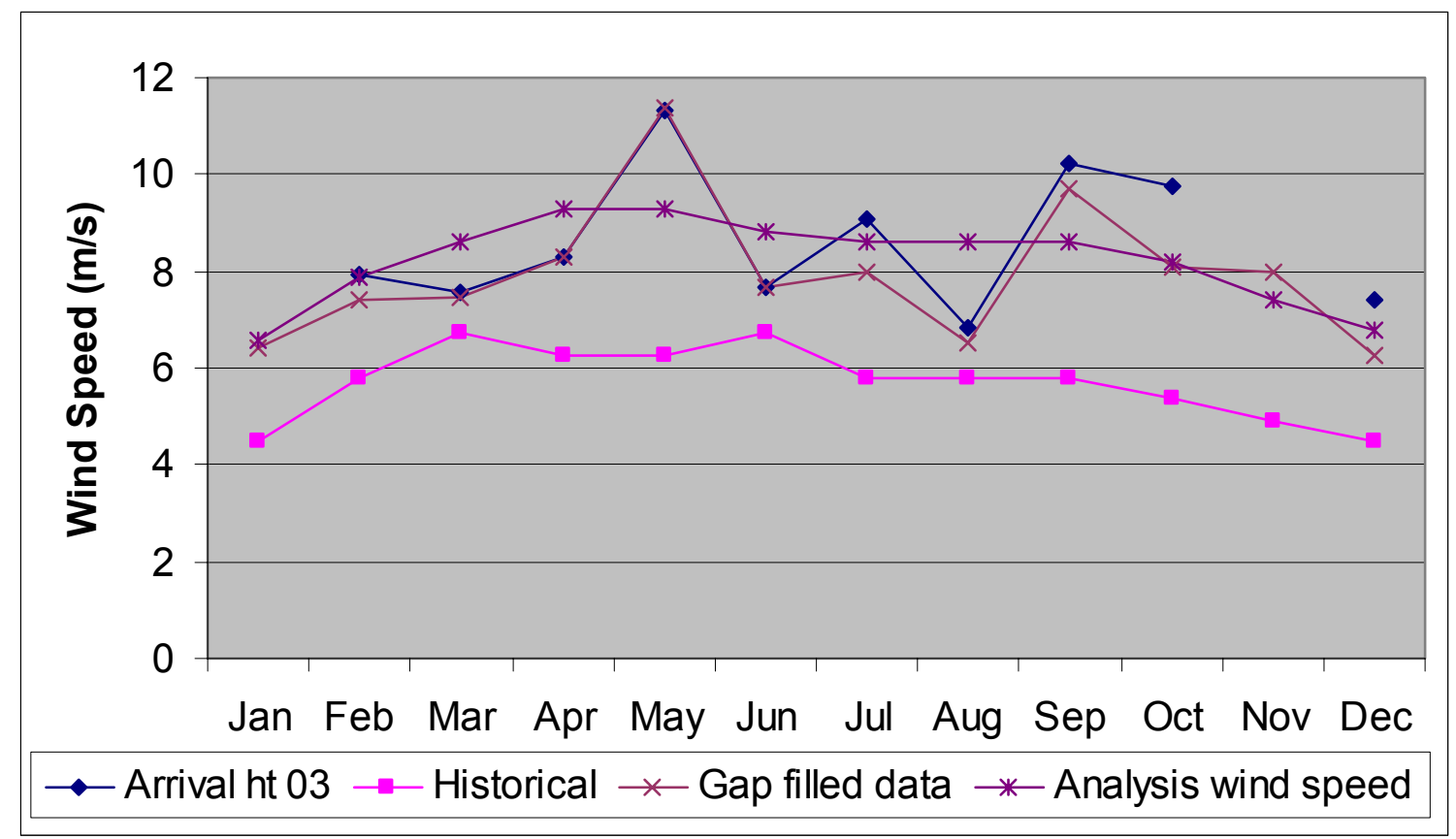

Figure 1. Wind speed data from Twin Craters (2003) and historical wind speed data from McMurdo Station 
Table 2: Summary of Collected 20-m Wind Speed Data from Three McMurdo Station Sites

\begin{tabular}{|c|c|c|c|c|c|c|c|c|c|c|c|}
\hline \multicolumn{4}{|c|}{ Crater Hill } & \multicolumn{4}{|c|}{ Twin Craters } & \multicolumn{4}{|c|}{ Snow Dump } \\
\hline Date & $\begin{array}{c}\text { Average } \\
\text { mph }\end{array}$ & $\begin{array}{l}\text { Gust } \\
\text { mph }\end{array}$ & $\begin{array}{c}\text { Direction } \\
\text { Polar }\end{array}$ & Date & $\begin{array}{c}\text { Average } \\
\text { mph }\end{array}$ & $\begin{array}{l}\text { Gust } \\
\text { mph }\end{array}$ & $\begin{array}{c}\text { Direction } \\
\text { Polar }\end{array}$ & Date & $\begin{array}{c}\text { Average } \\
m p h\end{array}$ & $\begin{array}{l}\text { Gust } \\
\text { mph }\end{array}$ & $\begin{array}{c}\text { Direction } \\
\text { Polar }\end{array}$ \\
\hline $1 / 25 / 03$ & & $\begin{array}{l}\text { Sensor } \\
\text { Installed }\end{array}$ & & $1 / 24 / 03$ & & $\begin{array}{l}\text { Sensor } \\
\text { Installed }\end{array}$ & & $1 / 29 / 03$ & & $\begin{array}{l}\text { Sensor } \\
\text { Installed }\end{array}$ & \\
\hline to $2 / 20$ & 14.9 & 56 & 146 & to $2 / 18$ & 16.7 & 108 & 200 & to $2 / 3$ & & Bad Data & \\
\hline 3/19/03 & 16 & 71 & 174 & 3/20/03 & 17.04 & 71 & 204 & 2/18/03 & 11.1 & 40 & 219 \\
\hline $4 / 19 / 03$ & 14.9 & 90 & 158 & 4/19/03 & 15.9 & 84 & 180 & 3/19/03 & 11.2 & 55 & 225 \\
\hline $5 / 20 / 03$ & 23.88 & 98 & 146 & $5 / 23 / 03$ & & Missing & & 4/19/03 & 11.3 & 63 & 221 \\
\hline 6/19/03 & 20.05 & 99 & 174 & $6 / 20 / 03$ & & Bad Data & & $5 / 20 / 03$ & 15.85 & 72 & 226 \\
\hline $7 / 5 / 03$ & 19.95 & 69 & 148 & $7 / 25 / 03$ & & Bad Data & & 6/19/03 & 13.28 & 85 & 229 \\
\hline $7 / 24 / 03$ & & Bad Data & & $7 / 26 / 03$ & & Missing & & $7 / 12 / 03$ & 12.5 & 50 & 228 \\
\hline $8 / 22 / 03$ & & Bad Data & & $8 / 22 / 03$ & 17.44 & 108 & 200 & & & Removed & \\
\hline \multirow[t]{8}{*}{ 10/1/03 } & & Bad Data & & $9 / 23 / 03$ & 17.81 & 95 & 159 & & & & \\
\hline & & Removed & & $10 / 13 / 03$ & 23.14 & 85 & 187 & & & & \\
\hline & & & & $12 / 9 / 03$ & & Bad Data & & & & & \\
\hline & & & & $12 / 23 / 03$ & & Missing & & & & & \\
\hline & & & & $1 / 8 / 2004$ & 15.74 & 55 & 159 & & & & \\
\hline & & & & $2 / 5 / 2004$ & 14.78 & 44 & 72 & & & & \\
\hline & & & & $3 / 4 / 2004$ & 15.35 & 62 & 56 & & & & \\
\hline & & & & $4 / 6 / 2004$ & 16.69 & 56 & 72 & & & & \\
\hline & Average & 18.28 & $\mathrm{mph}$ & & Average & 17.65 & $\mathrm{mph}$ & & Average & 12.538 & $\mathrm{mph}$ \\
\hline \multicolumn{2}{|c|}{ Maximum gust } & 99 & $\mathrm{mph}$ & \multicolumn{2}{|c|}{ Maximum gust } & 108 & mph & \multicolumn{2}{|c|}{ Maximum gust } & 85 & mph \\
\hline
\end{tabular}

It should be noted that the Crater Hill site experienced extremely high winds during May 2004, which is also reflected in data from the Snow Dump site. It appears that this was a singular event, so the wind speed for this month was scaled down to more accurately reflect the historical data. All data collection was completed at a 10-minute interval and 
averaged to 1 hour to use in the first level of system analysis. All measurements were conducted at 20 meters.

To conduct the analysis, available data from Twin Craters were used, which accounted for data from February 24 to April 19, September 22 to October 13, and December 23 to the end of the year. From April 19 to July 5, data from Crater Hill were used in the place of Twin Craters, except for a short period of absence of data in July. A scatter plot of concurrent wind speeds from February 25 to April 19 shows good correlation between the two data sets with Twin Craters from most directions. From July 5 to 13, data from Snow Dump were used with an appropriate scale factor, again based on comparisons between Twin Craters and Snow Dump. For the rest of the year, from December 1 to February 24 and from October 13 to December 23, no detailed time-series data exist. To assess the resources during these times, long-term historical data from McMurdo were used. A time series of the wind data used in the analysis is provided in Figure 2.

At the time of the analysis, approximately 8 months of actual site-related data were available, which is not sufficient to finalize the analysis for this system. It is critical that more data be obtained for the site to clarify the fall and winter wind profile and that the data be taken at a height of between 20 and 30 meters to more closely match the wind turbine's hub height.

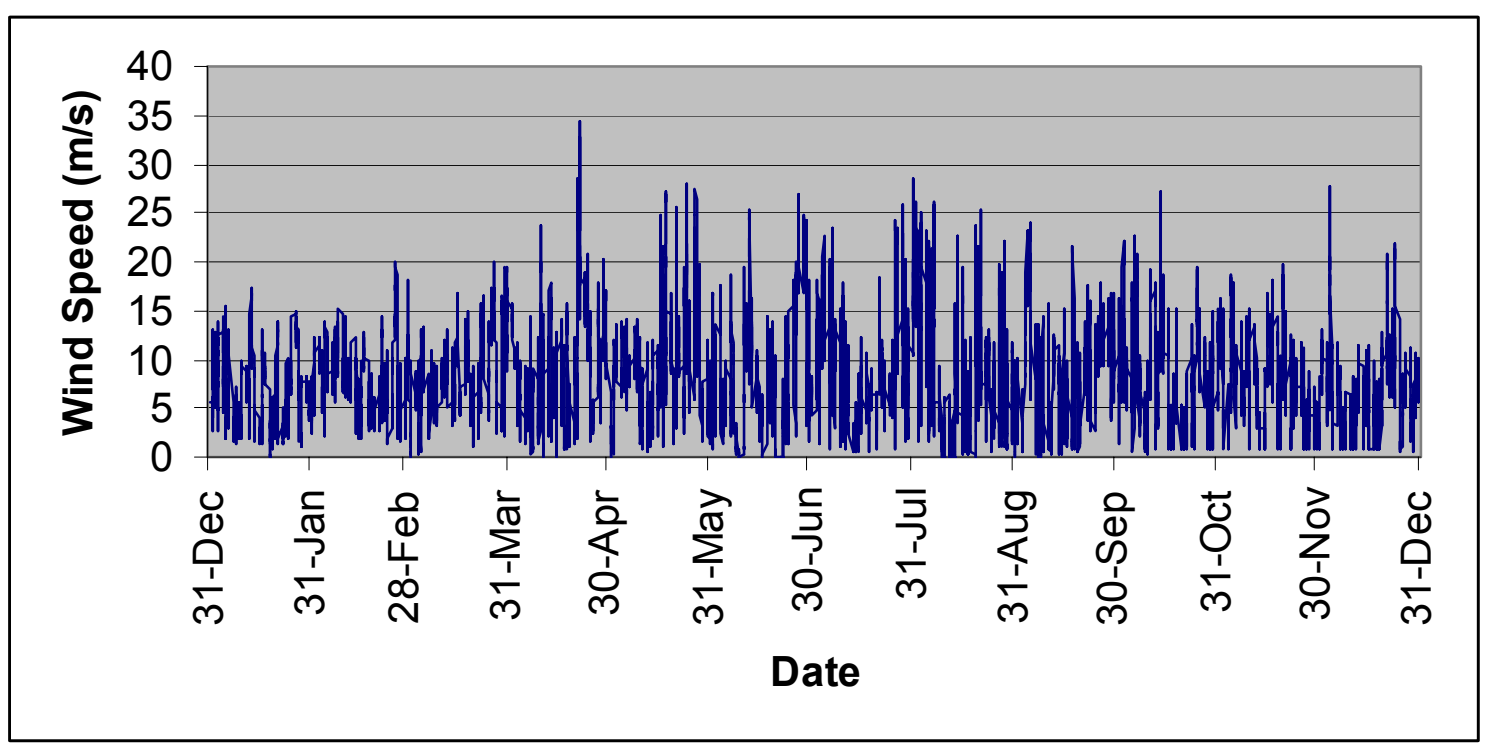

Figure 2: Wind speed data used in the analysis for McMurdo Station 
The maximum recorded wind speed at the sites for the year was more than $107 \mathrm{mph}$ (48 $\mathrm{m} / \mathrm{s}$ ), which is near the maximum range for a number of the turbines under consideration. Additionally, in March 2004, sustained wind speeds of $140 \mathrm{mph}(62.8 \mathrm{~m} / \mathrm{s})$, with gusts up to $188 \mathrm{mph}(84 \mathrm{~m} / \mathrm{s})$, were recorded at the NASA radar site located about 0.25 miles $(0.4$ $\mathrm{km}$ ) from the Twin Craters. This will be a critical issue in determining which turbine may be the most appropriate for the application.

\section{Load Data}

Raytheon Polar Services provided load data in the form of general plant output power every 10 minutes between December 2001 and March 2003. The monthly averages for these data are provided in Figure 3. Because of problems with the time step of the data files, we decided to use the full year of data from 2002. Year-to-year load growth varies between less than $1 \%$ to slightly more than $4 \%$, so although this will be considered in future analysis, we expect that the impact will be small.

Figure 4 depicts a plot of the time-series data used for the analysis.

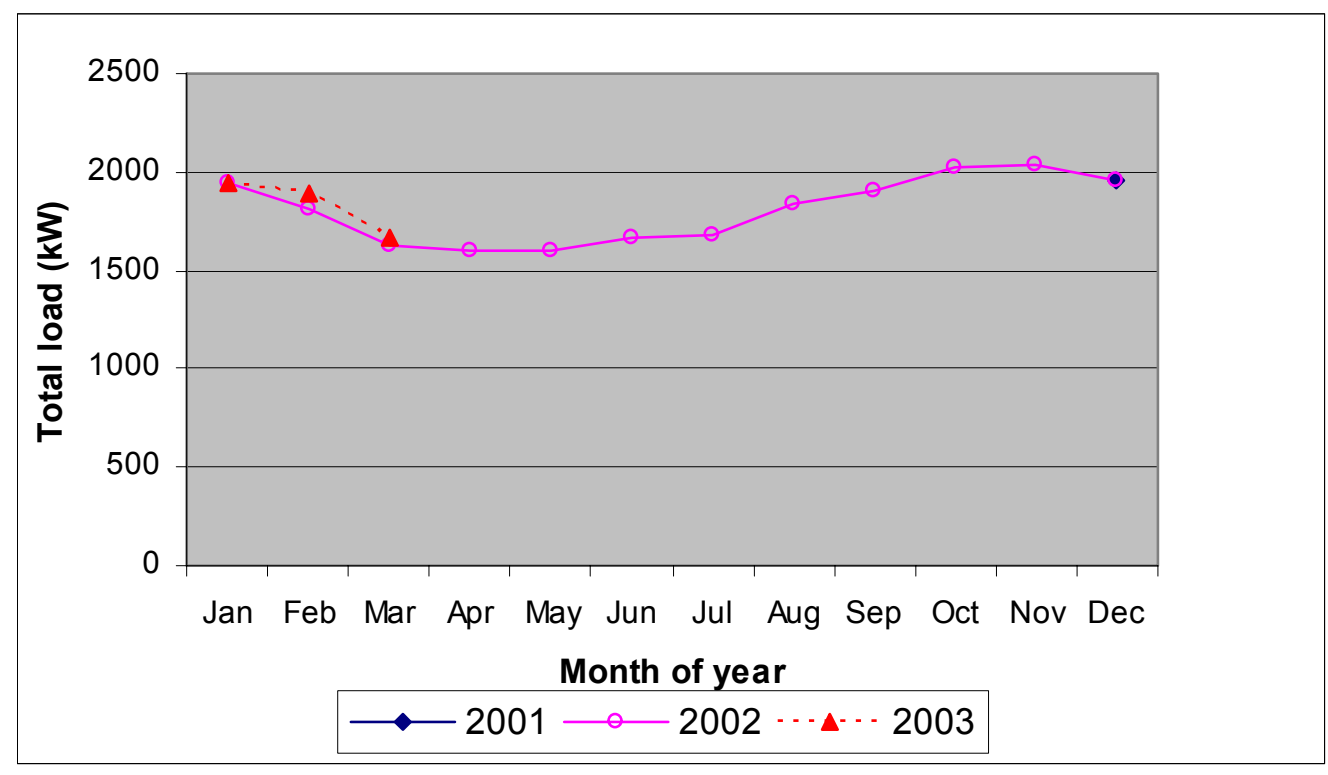

Figure 3: Historical load data for McMurdo Station 


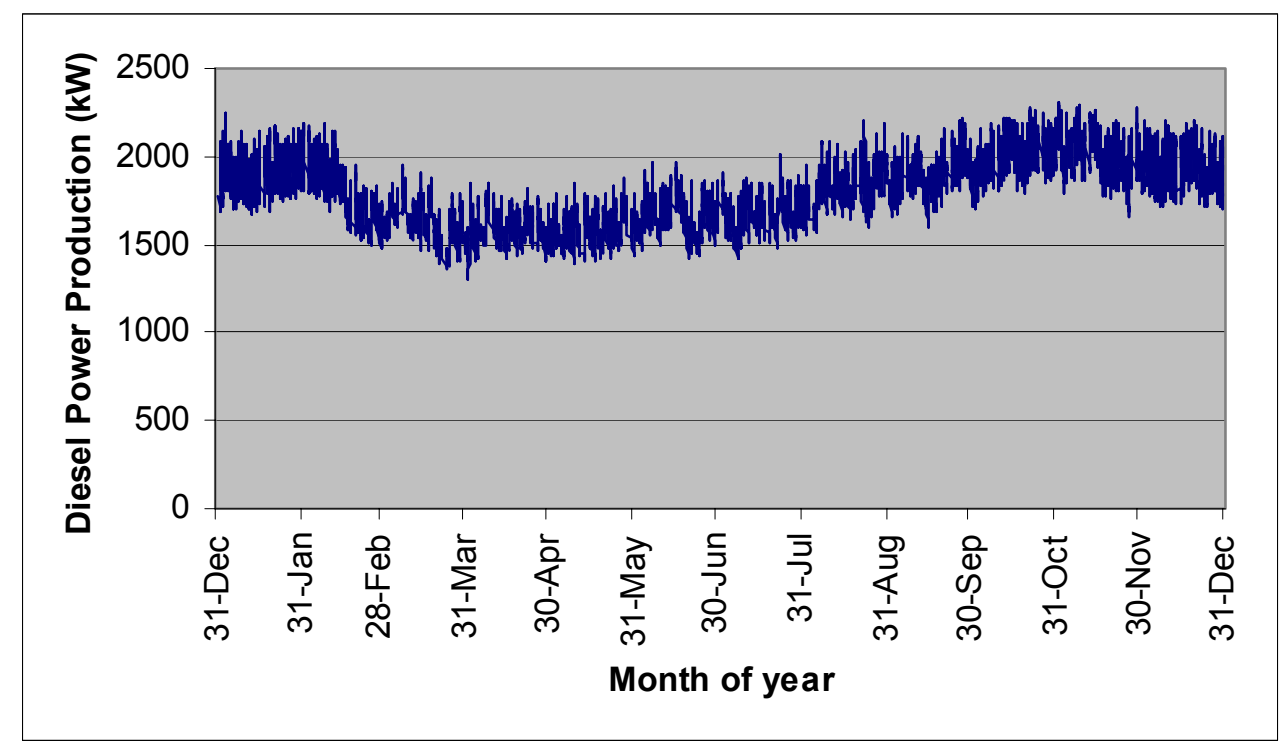

Figure 4: Load data used in the McMurdo Station analysis

\section{Diesel Plant}

The diesel plant was modeled using six Caterpillar $1418 \mathrm{kVA}(1135-\mathrm{kW})$ prime power diesel gensets driven by 3512B diesel engines. This model was completed because of an inability to access data on gensets based on the Caterpillar 3516B diesel. Additionally, the specific size and ranking of the diesels to be used in the new McMurdo power house were not known. Once the size of the diesels is known, data can be obtained on the specific diesel engines to be used. Typically three diesels are operational to allow reserve capacity.

One additional simulation was completed, including a smaller 600-kW (750-kVA)

Caterpillar generator based on a 3508B diesel engine to determine whether allowing more refined sizing would impact system costs.

\section{Retrofitting Constraints}

Several constraints need to be defined before further analysis can be conducted. The site at Twin Craters is constrained in size, which will limit the number of wind turbines that could be installed at this location. The ridge, which fortunately lies perpendicular to the pervading wind direction (Figure 5), measures about $700 \mathrm{ft}(230 \mathrm{~m})$ long and $150 \mathrm{ft}$ (50 $\mathrm{m})$ wide. The crane at McMurdo that could be used to install the turbine has a maximum lift height of 135 feet $(44.3 \mathrm{~m})$ and has a maximum lift capability of $10,500 \mathrm{lb}(4762 \mathrm{~kg})$. The capacity of the crane will limit the size of the wind turbine that could be installed. 


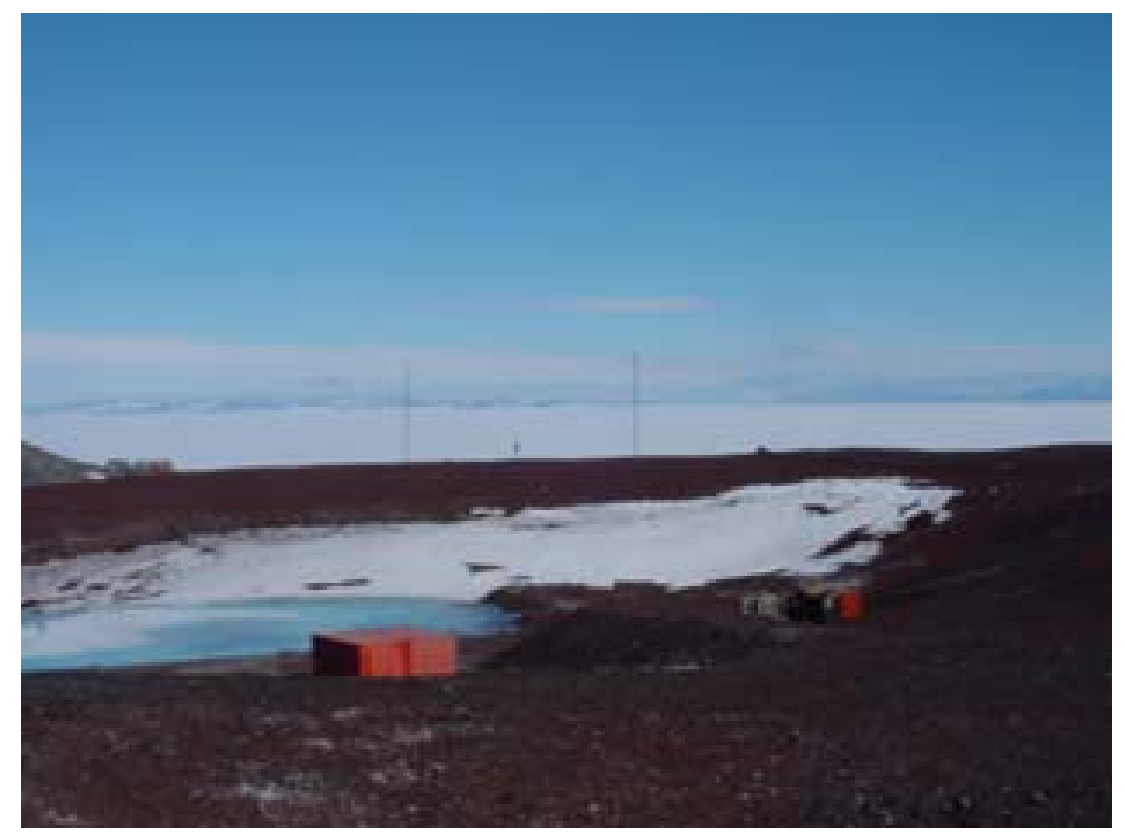

Figure 5: Twin Craters overlooking the McMurdo Station

\section{Results of McMurdo Station Options Analysis}

McMurdo has a large energy demand and is constrained by space limitations at Twin Craters. This means that only a limited number of wind turbines could be installed at this site, limiting the potential installed wind capacity.

Based on the assumed diesel power station configuration, manufacturer's fuel consumption information, and the measured load, a fuel consumption of 4,878,225 liters was estimated using the Hybrid2 software. This can be compared to the 4,921,000 liters that was consumed by the old diesel plant in 1999. The new diesel plant will have higher efficiency, but the load has also increased, and the close proximity of these numbers adds some credence to the analysis methodology. Based on this consumption, the cost of energy based only on diesel fuel is $\$ 0.1589 / \mathrm{kWh}$.

For this first level of analysis, two turbines were considered: the Northwind 100/19 (the standard form of the 100-kW Northwind turbine) and the Furlander FL 250 (a standard $250-\mathrm{kW}$ wind turbine). Both of the turbines used in the analysis meet the requirements of the crane at McMurdo station.

The minimum spacing of a wind turbine is two rotor diameters, but this is highly dependent on a wind rose for the site, which has not been completed because of the lack of reliable wind direction data. Based on the dimensions of the Twin Crater site, which is $700 \mathrm{ft}(230 \mathrm{~m})$ long, it would be possible to place as many as five $\sim 250-\mathrm{kW}$ wind turbines, although four would be more likely. If smaller turbines were used, a total installed capacity would likely be smaller, although more turbines would be used. The analysis examined using seven Northwind turbines with a total installed capacity of 700 $\mathrm{kW}$ and then two installations of the Furlander FL 250, five turbines with a nominal 
installed capacity of $1250 \mathrm{~kW}$ and four turbines with nominal installed capacity of 1000 $\mathrm{kW}$. It should be noted that the actual maximum performance of the Furlander FL 250 is actually $300 \mathrm{~kW}$ at a wind speed of $21 \mathrm{~m} / \mathrm{s}(\sim 47 \mathrm{mph})$.

Based on simulations using the Hybrid2 software, the amount of fuel consumed and the overall cost of energy decreases with the inclusion of wind energy. Table 3 shows the results of several different power system configurations using different wind turbines. The potential fuel savings depends on the system selected, but ranges from $13 \%$ to $24.9 \%$, with a maximum fuel savings of more than 320,700 gallons/year $(1,214,000$ liters/year). Based on the 2002 electrical energy use, which averages between 1.5 and 2.0 MW, up to $25 \%$ of the station's electrical energy would be generated by wind.

Table 4 provides on overview of expected project economics based on the analysis of the same system configurations introduced in Table 3 . In this table, the capital cost of several different options is provided, along with the systems 20 -year net present cost (NPC), or the total cost of the power system for the next 20 years. A reduced NPC indicates that this option is less expensive on a life-cycle basis. Cost of energy (COE) is also provided, though care should be used when looking at these numbers because not all power system costs, such as operators and other infrastructure expenses, have been included in the analysis as the use of wind power is not likely to change these costs. A number that provides more information is the figure representing the difference in COE produced. This number shows, based on the items that were included in this analysis (primarily diesel fuel, system operation, maintenance, and capital costs), the expected reduction in costs using different system configurations.

Table 3: Performance Impact of Using Wind Energy at McMurdo Station

\begin{tabular}{|c|c|c|c|c|c|c|}
\hline \multirow{2}{*}{$\begin{array}{l}\text { Input } \\
\text { Type of } \\
\text { Turbine }\end{array}$} & \multirow[b]{2}{*}{$\begin{array}{c}\text { \# of } \\
\text { Turbines }\end{array}$} & \multirow{2}{*}{$\begin{array}{c}\text { Installed } \\
\text { Nominal } \\
\text { Capacity } \\
(\mathrm{kW})\end{array}$} & \multirow[b]{2}{*}{$\begin{array}{c}\text { Engine } \\
\text { Size }(k W)\end{array}$} & \multicolumn{2}{|c|}{$\begin{array}{l}\text { Performance } \\
\text { Results }\end{array}$} & \multirow[b]{2}{*}{$\begin{array}{c}\text { Fuel } \\
\text { Savings } \\
\text { I/yr }\end{array}$} \\
\hline & & & & $\begin{array}{c}\text { Fuel used } \\
\text { I/yr }\end{array}$ & $\begin{array}{c}\text { Fuel } \\
\text { Savings } \\
\%\end{array}$ & \\
\hline \multicolumn{2}{|c|}{ All diesel system } & & & 4878225 & $\mathrm{n} / \mathrm{a}$ & $\mathrm{n} / \mathrm{a}$ \\
\hline NW 100 & 7 & 700 & $6 \times 1135 \mathrm{~kW}$ & 4243632 & 13 & 634593 \\
\hline FL 250 & 4 & 1000 & $6 \times 1135 \mathrm{~kW}$ & 3876228 & 20.5 & 1001997 \\
\hline FL 250 & 4 & 1000 & Small Dsl & 3696438 & 24.2 & 1181787 \\
\hline FL 250 & 5 & 1250 & $6 \times 1135 \mathrm{~kW}$ & 3664099 & 24.9 & 1214126 \\
\hline
\end{tabular}


Table 4: Economic Impact of Using Wind Energy at McMurdo Station

\begin{tabular}{|c|c|c|c|c|c|c|c|}
\hline \multirow{2}{*}{$\begin{array}{l}\text { Input } \\
\text { Type of } \\
\text { turbine }\end{array}$} & \multirow[b]{2}{*}{$\begin{array}{c}\text { Turbine } \\
\quad \#\end{array}$} & \multirow[b]{2}{*}{$\begin{array}{l}\text { Engine } \\
\text { Size }(k W)\end{array}$} & \multicolumn{3}{|c|}{ Economic Results } & \multirow[b]{2}{*}{ 20-Year NPC } & \multirow[b]{2}{*}{$\begin{array}{l}\text { Capital } \\
\text { Cost, \$ }\end{array}$} \\
\hline & & & $\begin{array}{l}C O E \\
\$ / k W h\end{array}$ & & $\begin{array}{l}\text { ference } \\
\text { Wh prod }\end{array}$ & & \\
\hline \multicolumn{2}{|c|}{ All diesel system } & & $\$ 0.1589$ & $\$$ & - & $\$ 30,809,210$ & $\$$ \\
\hline NW 100 & 7 & $6 \times 1135 \mathrm{~kW}$ & $\$ 0.1542$ & $\$$ & 0.0047 & $\$ 29,889,266$ & $\$ 2,302,886$ \\
\hline FL 250 & 4 & $6 \times 1135 \mathrm{~kW}$ & $\$ 0.1423$ & $\$$ & 0.0166 & $\$ 27,589,012$ & $\$ 2,140,400$ \\
\hline FL 250 & 4 & Small Dsl & \$ 0.1377 & $\$$ & 0.0212 & $\$ 26,693,168$ & $\$ 2,140,400$ \\
\hline FL 250 & 5 & $6 \times 1135 \mathrm{~kW}$ & $\$ 0.1383$ & $\$$ & 0.0206 & $\$ 26,824,676$ & $\$ 2,675,500$ \\
\hline
\end{tabular}

Given these cases, the use of wind energy at McMurdo could reduce the total cost of generating power by between $1 / 2$ a cent to 2 cents per $\mathrm{kWh}$. Over a 20 -year expected life of the equipment, the total savings, including all capital costs, ranges between $\$ 1$ million and $\$ 4$ million, although most wind turbines have a design life of 30 years.

The analysis also demonstrated that the inclusion of a smaller peaking diesel also makes economic sense, resulting in almost a $4 \%$ reduction in fuel consumption. The new diesel plant at McMurdo will include two smaller peaking diesels, but some analysis might be warranted to determine their optimal size, even if wind energy is not to be included in the power system redesign.

As stated previously, this analysis does not include the impact of the reduced waste heat from the generators based on the reduction in fuel consumption. Because the diesel engines will continue to be used even while the turbines are operating, thermal energy from these units will still be available to provide existing heating loads. However, a reduction in the amount of fuel consumption will have an impact on the amount of heat available for other loads. A technical and economic assessment will have to be conducted to determine the impact of the loss of waste heat from the diesel plant.

Costs associated with reducing the need for fuel storage at McMurdo has not been included in this analysis but will add additional savings. 


\section{Further Data Needed to Refine the McMurdo Analysis}

The following data should be obtained to refine the analysis conducted as the basis of this report.

\section{Load}

- Better understanding of the thermal loading systems

- Information on the Reverse Osmoses (RO) water desalination unit, power rating, fresh water storage capacity, and usage

- Temperature data for the site (to determine thermal energy requirements)

- Temperature setting for the buildings (to determine temperature coefficient)

- Updated station electrical energy requirements.

- Conduct a detailed energy audit of current and planned buildings

Diesel Plant

- Clarification of the current diesel configuration, unit specification, and size

- Fuel-use curves of the diesel engines on site

- Updated information on fuel price, usage, and storage availability

- Costs of expected fuel storage expansion.

\section{Wind Data}

- Additional wind speed data from Twin Craters at a height of $20 \mathrm{~m}$ to $30 \mathrm{~m}$

- Historical wind data from McMurdo Station

- Wind rose for Twin Craters anemometry.

\section{Constraints}

- Further analysis of Twin Craters site, including soil type, road rating, power line extension, etc.

- Analysis of potential impact of wind turbines on any ongoing or planned scientific experiments 


\section{Amundsen-Scott South Pole Station}

\section{Existing Conditions}

At a 9,400-ft physical elevation (11,000-ft physiological elevation) and with temperatures ranging from $-115^{\circ} \mathrm{F}$ to $+6^{\circ} \mathrm{F}\left(-82^{\circ} \mathrm{C}\right.$ to $\left.-14^{\circ} \mathrm{C}\right)$, South Pole Station sits on a slowly moving Polar Plateau ice field at the earth's geophysical south pole spin axis. The station supports year-round scientific activity, and the original dome facility is currently being replaced by a new above-snow facility that will greatly expand the services and living conditions at the Pole. As part of this major redevelopment activity, the power plant was completely redesigned, and the primary generator waste heat (engine jacket and exhaust) is fully captured and distributed to various buildings.

One limiting factor at South Pole is that all supplies, equipment, and personnel must be flown into the site during a short, 4-month summer season. The large amount of diesel fuel needed to power and heat the station continues to constrain the cargo capacity and places extreme logistics and performance pressure on support personnel, scientific research, and station services. As the electrical needs at the site grow, this problem continues to worsen. Additionally, the cost of transporting fuel by air raises the price of the fuel to well over $\$ 10 /$ gallon. The utilization of wind power to replace some amount of diesel consumption is one option to reduce the required import costs. Other options, such as developing a land-based supply train, are also being investigated.

The energy requirements of the South Pole station are difficult to obtain, primarily because the station is in the process of receiving a major upgrade. In the 1999 to 2000 year, fuel consumption for power generation was 258,284 gallons (977,708 liters) per year, which makes up approximately $71 \%$ of the fuel consumption at the site. These numbers apply to the operation of the older diesel power plant, which was replaced in 2001 and 2002, and the older facilities. Yearly fuel usage for the new diesel power plant at the new facility is projected to be 341,000 gallons (1,290,821 liters). Based on current consumption, power generation requires the importation of 1,160 short tons $(1,052$ metric tons) of fuel to the station.

Research and installation of small-scale towers and wind turbines at the South Pole has provided valuable hands-on experience with some of the critical issues. Challenges to be overcome are many, including efficient transport of materials to the site; snow foundation design; improvements to cold-hardened equipment; operation, maintenance, and repair issues; and mitigation of possible electromagnetic interference. Each of these issues will have to be considered as part of any project-development or detailed analysis process.

\section{Wind Speed Data}

Almanac data state that the average wind speed for 2000 was $11.5 \mathrm{mph}(5.14 \mathrm{~m} / \mathrm{s})$ with a maximum wind speed of $45 \mathrm{mph}(20.1 \mathrm{~m} / \mathrm{s})$, whereas the average for 2001 was $12.4 \mathrm{mph}$ $(5.54 \mathrm{~m} / \mathrm{s})$ with a maximum wind speed of $44 \mathrm{mph}(19.7 \mathrm{~m} / \mathrm{s})$. It is also reported that the 
wind speed is in excess of $5.0 \mathrm{~m} / \mathrm{s}$ approximately $70 \%$ of the time, although this cannot be confirmed.

\section{Energy Consumption}

Load data are available for the existing South Pole station and averages 384 kilovolt amperes (kVA). Thermal energy from the generator's water and jacket heat will be used for space heating of the primary station buildings and to melt ice for water. Energy estimates for this new facility places usage at around $500 \mathrm{~kW}$, ranging from $467 \mathrm{~kW}$ during the summer and $510 \mathrm{~kW}$ during the winter, although this has not been confirmed. Using John Rand's analysis, every extra MWh of supplanted diesel power will require the import of 48 gallons (181 liters) of fuel for heating.

\section{Diesel Power Plant}

The current power plant, installed in 2001 as part of the station retrofit, is made up of three Caterpillar 3512 diesels with $750-\mathrm{kW}$ generators and one Caterpillar 3412, 250-kW generator. One of the larger generators operates continuously, alternating operation, while an additional large unit is on standby. The $250-\mathrm{kW}$ diesel is used for peaking.

\section{Local Information}

The cost of shipping equipment to the South Pole from McMurdo is about $\$ 1.57 / \mathrm{lb}$ $(\$ 3.47 / \mathrm{kg})$. This results in a total cost of shipping equipment from the United States by air and ship at $\$ 2.97 / \mathrm{lb}(\$ 6.55 / \mathrm{kg})$ and $\$ 1.74 / \mathrm{lb}(\$ 3.83 / \mathrm{kg})$, respectively. Delivered diesel fuel at the South Pole cost is projected to be between $\$ 12.00$ (\$3.17/l) and $\$ 15.70$ (\$3.78/liter) per gallon (John Rand report).

\section{Analysis of South Pole Station Wind Power Options}

This section describes the data used in the analysis for South Pole Station, as well as the assumptions regarding installation and the operation of the current diesel power stations. This initial analysis primarily examines the amount of wind energy that could easily be absorbed into the diesel grid at the South Pole Station. It also describes wind energy equipment options and further information needed to allow refinement of the analysis.

The analysis of the retrofit potential as a high-penetration power system of the South Pole Station was more expansive than the analysis of McMurdo. Given the energy consumption and space limitations at McMurdo, this station would not have been suitable for such a power system. It is assumed that the implementation of a high-penetration power system at the South Pole would be a slow process, which would likely start with the installation of a small number of wind turbines with the appropriate control equipment to gain operation experience before more turbines were installed. Assuming the wind turbine operation was satisfactory, it would be expected that the implementation of the complete system would take place over 3 to 5 years. This report discusses the initial stage of this activity only, leaving analysis of more extravagant options, such as a no-diesel wind and stored hydrogen power system, for another time. 


\section{Turbines Used in the Analysis}

Currently, no utility-scale wind turbines are available that have a low enough temperature rating to enable operation at the extreme temperatures found at South Pole. The only turbine that comes close to fulfilling the temperature requirements is the NorthWind 100 by Northern Power Systems, although some cold-related development work is still needed on this product. One of the modifications for this turbine will likely include the use of an enlarged rotor (20-m diameter instead of the standard 19.1-m rotor) to improve power capture in the lower wind speed environment of the South Pole. The standard NorthWind 100 was used for this analysis although additional costs have been added to the base cost of the turbine to account for the additional modifications required for an Antarctic version. The costs do not include development expenses to lower the operating temperature of the turbine below $-100^{\circ} \mathrm{F}\left(-73^{\circ} \mathrm{C}\right)$.

Low-maintenance, high-durability vertical-axis turbines from Finland's Oy Windside are also presently used successfully at Finland's Antarctic research station. The largest Windside presently available is rated at $22 \mathrm{~kW}$, which is small for such applications, but demonstrates that as part of further analysis, more research on available technologies should be conducted (Windside).

A Mantis 6610 crane manufactured by Spandek is available at the South Pole Station that can be used to install wind turbines. It is rated at 33 tons ( 29.9 metric tons ) and, with the jib installed, it has a max boom of 110 feet ( 33.5 meters ).

\section{Wind Data}

Wind data for 2003 were used for the analysis of wind potential at the South Pole Station. In this initial analysis, hourly wind speed values taken at the South Pole Metrological Station were used, although no specific information is available regarding the exact placement and height of this measurement. Figure 6 shows the time series used for the analysis. A histogram of the data indicates that the wind was below $5 \mathrm{~m} / \mathrm{s}$ only $23 \%$ of the time for 2003 and had an average value of $5.3 \mathrm{~m} / \mathrm{s}$, in the range expected from historical data.

\section{Load Data}

The time-series data used for this analysis are based on plant output from October 2001 to October 2002, which represents the use of the old facility. The data do not show a strong diurnal or seasonal variation, which is similar to other summary data for the site. Little information is available on the energy consumption of the new facility currently being constructed, other than the range provided in the earlier section of this report. To allow analysis of the new facility, the load time series from the old station was scaled to represent the expected loads for the new station. The yearly load profile used in the analysis is shown in Figure 7. 


\section{Temperature Data}

Temperature data from the South Pole for 2003 show the characteristic, highly seasonal, low temperatures (Figure 8). The lowest hourly temperature recorded for 2003 was negative $73^{\circ} \mathrm{C}$.

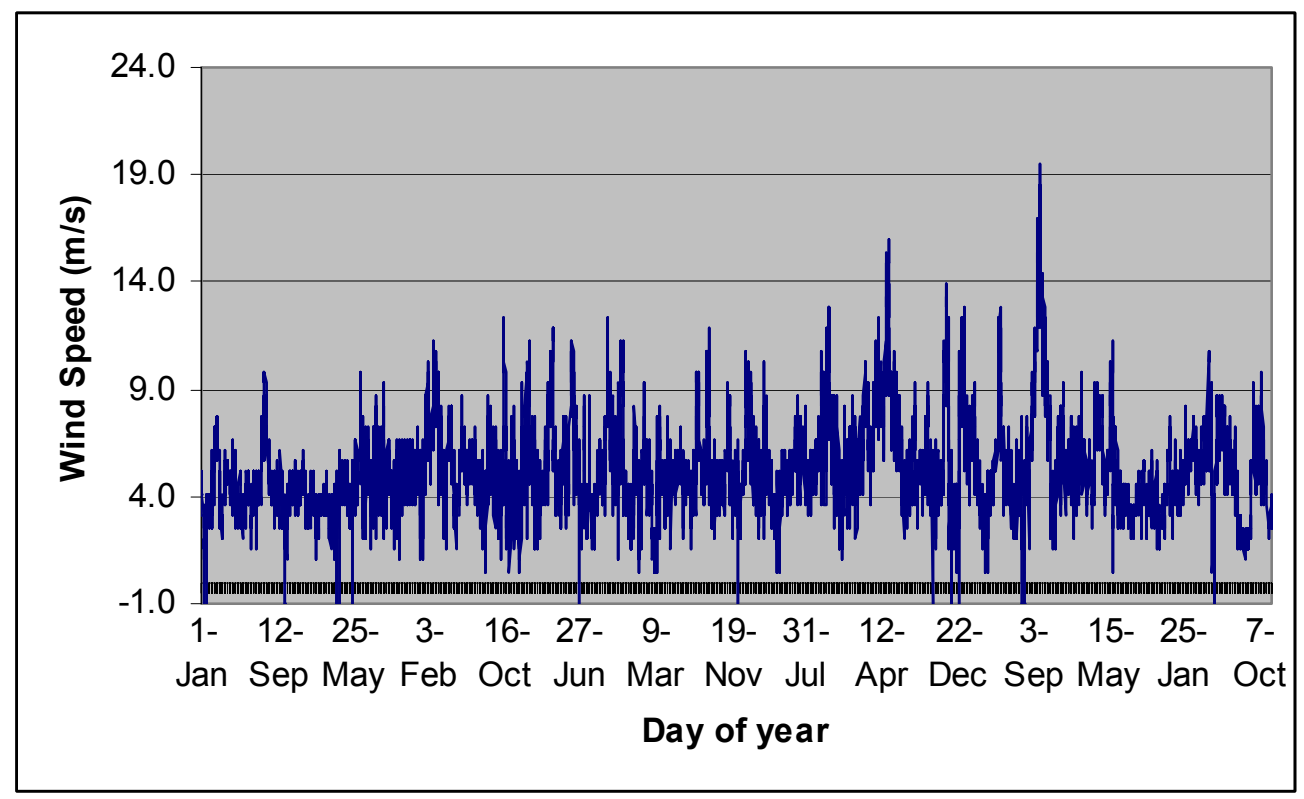

Figure 6: Wind speed measurements taken at the South Pole metrological station for 2003

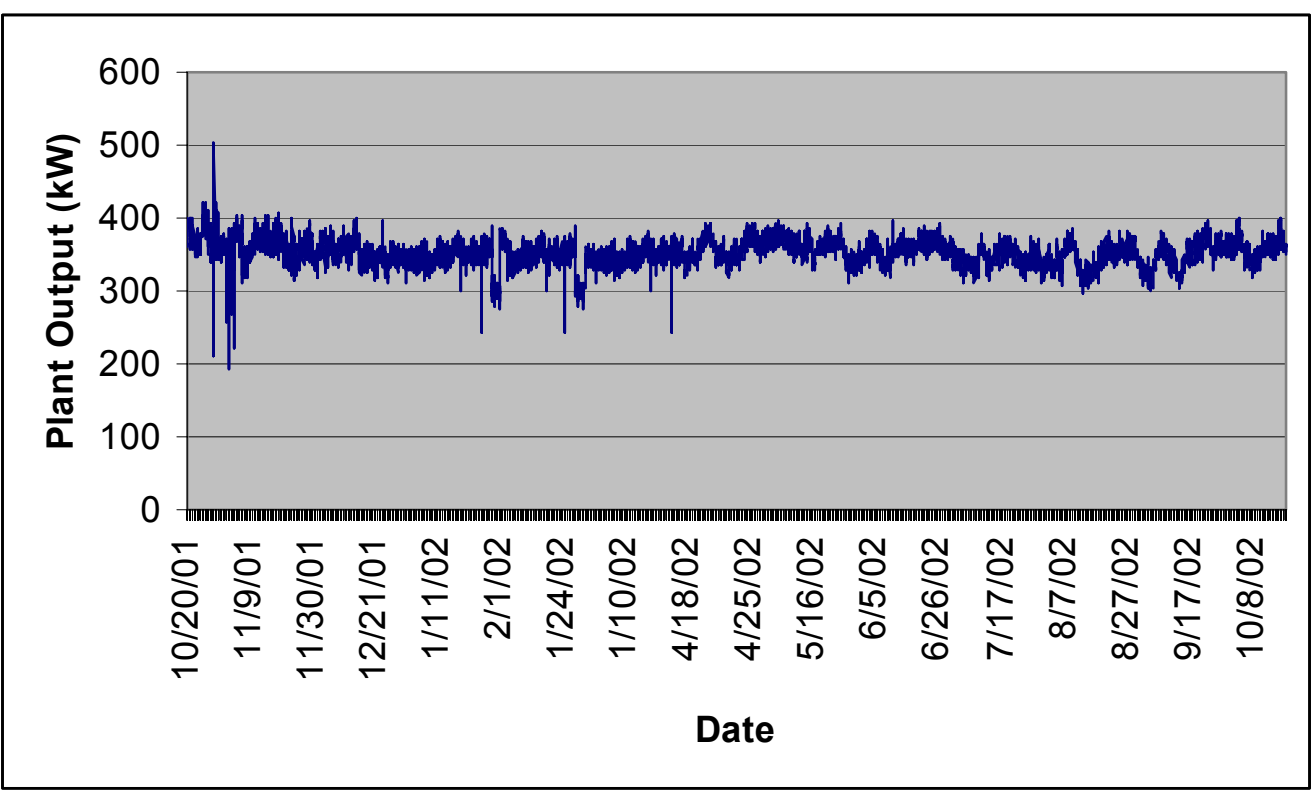

Figure 7: Energy output of the new South Pole Station diesel plant from October 1, 2001 to October 6, 2002 


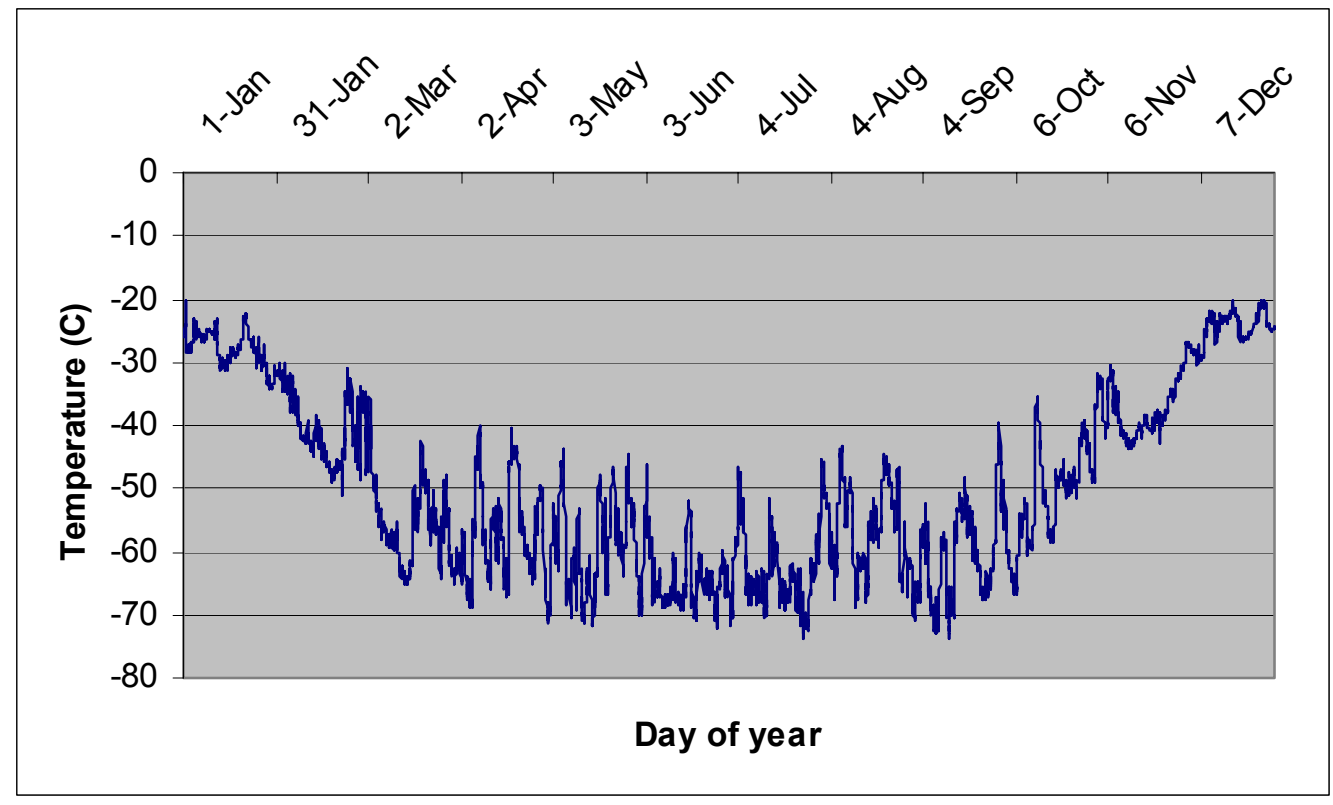

Figure 8: Temperature measurements taken at the South Pole metrological station for 2003

\section{Diesel Plant}

The report produced by John Rand stated that the new diesel plant would consist of three Caterpillar 3512 generators $(750 \mathrm{~kW})$ and one Caterpillar 3412 diesel generator $(250$ $\mathrm{kW}$ ). In conducting research for the plant, it was determined that the Cat 3512 is usually matched with a $1135-\mathrm{kW}$ generator and the 3412 with a $725-\mathrm{kW}$ generator. In this analysis, the fuel curves for the Cat $3412 \mathrm{C}$ and $3512 \mathrm{~B}$ were used, assuming a maximum rated power as provided by the Rand report: 250 and $750 \mathrm{~kW}$, respectively. This results in much higher annual fuel consumption (1,978,231 liters/year) compared to the amount predicted in the Rand report (1,298,800 liters/year). This should be clarified in further analysis.

Costs associated with reducing the need for fuel storage at the South Pole have not been included in this analysis but should be assessed in any further investigation.

\section{Results of South Pole Station Options Analysis}

Because any wind energy project at the South Pole will start small, the analysis of this option is quite simple. The Hybrid2 software was used to determine the power performance and economic cost of installing an increasing number of wind turbines. Performance is based primarily on the known wind speed, load, and performance of the wind turbine and diesel plant.

As stated previously, there is a large discrepancy in the expected fuel consumption between the estimations in John Rand's report and those achieved in modeling the system. This difference should be clarified because it will clearly impact the overall cost 
effectiveness of installing wind power. Based on the load, the expected diesel fuel consumption for the new South Pole station is estimated to be 341,000 gallons/year $(1,298,800$ liters/year)

As a result of the relatively low wind speeds assumed at the site, the impact of installing wind turbines is limited, but it is still quite cost advantageous. Figure 9 displays the results of simulating between one and $10100-\mathrm{kW}$ wind turbines at the South Pole.

Additional results are included in Table 5. The upper limit of 10 wind turbines was used because of the issues of penetration and simply the sheer number of wind turbines. This system would constitute a low- to medium-penetration power system (see appendix); thus few additional systems controls would be required. The installation of nine $100-\mathrm{kW}$ wind turbines at the site would provide about $50 \%$ of the station's annual power demand in addition to $960 \mathrm{MWh}$ of energy that could be used for heating or other direct-process applications. The use of nine turbines would reduce fuel consumption by almost $23 \%$ (440,783 liters/year). The investigation of a power system using more wind, although likely to be economic, would require the installation of many more wind turbines with diminishing returns for the installation of each additional turbine. However, the installation of more wind turbines could reduce diesel fuel consumption significantly and should be investigated once more experience has been gained in using wind power at the Pole. The total capital cost of installing nine turbines would be approximately $\$ 4.3$ million.

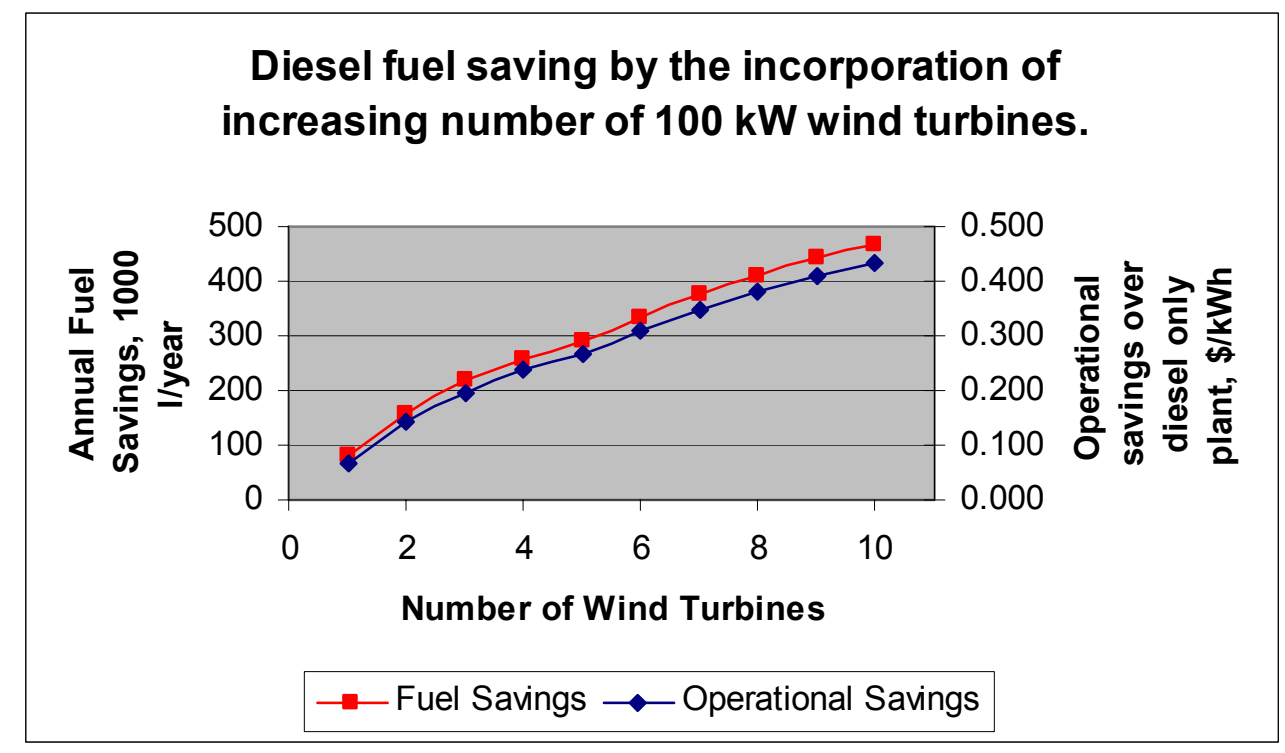

Figure 9: Results of the wind energy use analysis at the South Pole Station 
Table 5: Economic Impact of Using Wind Energy at South Pole Station

\begin{tabular}{|c|c|c|c|c|c|c|}
\hline \multirow{2}{*}{$\begin{array}{c}\text { Input } \\
\text { Turbine }\end{array}$} & \multicolumn{3}{|c|}{ Performance Results } & \multicolumn{3}{|c|}{ Economic Results } \\
\hline & Fuel Savings & $\begin{array}{c}\text { Energy from } \\
\text { Wind }\end{array}$ & $\begin{array}{c}\text { Extra } \\
\text { Energy* }^{*}\end{array}$ & Savings & $\begin{array}{c}\text { Simple } \\
\text { Payback }\end{array}$ & Capital Cost \\
\hline \# & $1000 \mathrm{l} /$ year & $\%$ & $\mathrm{MWh} / \mathrm{yr}$ & $\$ / k W h$ & $\mathrm{yr}$ & $M \$$ \\
\hline 0 & 0.0 & 0.0 & 0 & 0 & 0 & 0 \\
\hline 1 & 82.0 & 5.9 & 1.6 & 0.055 & 1.84 & 0.468 \\
\hline 2 & 159.0 & 11.7 & 27.5 & 0.115 & 1.77 & 0.935 \\
\hline 3 & 216.7 & 17.6 & 110.2 & 0.158 & 1.91 & 1.403 \\
\hline 4 & 258.5 & 23.5 & 240.3 & 0.187 & 2.11 & 1.870 \\
\hline 5 & 290.1 & 29.4 & 400.6 & 0.206 & 2.34 & 2.338 \\
\hline 6 & 334.6 & 35.2 & 517.6 & 0.237 & 2.42 & 2.805 \\
\hline 7 & 376.4 & 41.1 & 645.9 & 0.386 & 2.45 & 3.293 \\
\hline 8 & 411.4 & 47.0 & 795.6 & 0.288 & 2.61 & 3.740 \\
\hline 9 & 440.8 & 52.9 & 961.2 & 0.305 & 2.74 & 4.208 \\
\hline 10 & 468.1 & 58.7 & 1131.1 & 0.320 & 2.86 & 4.675 \\
\hline
\end{tabular}




\section{Further Data Needed to Refine the South Pole Station Analysis}

The following data should be obtained to refine the analysis conducted as the basis of this report.

\section{Load}

- Conduct a detailed energy audit of current and planned buildings

- Updated estimates of the expected load for the new South Pole facility

- Estimate of the total thermal energy loads for the building and auxiliary energy needs, such as melting ice for water.

Diesel Plant

- Clarification of the current diesel configuration, unit specification, and size

- Fuel-use curves of the diesel engines on site

- Updated information on fuel price, usage, and storage availability

- Costs of expected fuel storage expansion.

\section{Wind Data}

- Measurement of free-stream airflow at a height of $20 \mathrm{~m}$ or $30 \mathrm{~m}$, upwind of the station in a location where turbine installation would be possible.

\section{Constraints}

- Specification of available area for a proposed wind farm in proximity to the South Pole station

- Analysis of potential impact of wind turbines on any ongoing or planned scientific experiments

- Specification of maximum transport and pull force available at the South Pole. 


\section{Conclusion}

Based on the results of this analysis, there is clear potential to use wind energy to reduce the power generation costs, harmful air emissions, and fuel needs at both stations.

This initial analysis indicates that a large potential savings could be realized by incorporating wind energy into the existing diesel plants at the South Pole Station. The economic impact of using wind power at McMurdo is not as extreme, but it is cost effective and would significantly reduce diesel fuel consumption. Given the amount of wind energy that could be included in the systems at McMurdo and South Pole Station, the current diesel plants will continue to operate, at least initially, as they currently are. Any savings will result from a reduction in fuel consumption and subsequent reduced fuel storage requirements.

Both of these analyses are based on data that are generally out of date or limited in nature; thus the results should be considered preliminary. However, even with the limitations of the data used in the analysis, the increasing electric demand (which leads to increased fuel storage and transportation needs) and the growing cost of diesel fuel will only make wind more financially attractive in any further analysis. The study did not assess the impact of reduced heat availability from the diesel plants or the economic impact of reducing the size of diesel fuel storage expansion.

To advance the assessment of these opportunities, several steps should be taken at the McMurdo and South Pole stations. These include obtaining better load and power system data following a detailed energy audit of each station; more advanced wind measurement at McMurdo and initiating a wind site-specific measurement program at South Pole. Additionally, further analysis is required to quantify the impact of reducing the available 'waste' heat from the generators due to the reduction of diesel generator electrical output.

If it were determined that this opportunity was to be pursued, the next step would be to collect the data called for in this report and then conduct a more detailed assessment of potential options, turbines, and systems specifications. 


\section{References}

As mentioned in the introduction, information used in the report was largely obtained from unpublished reports: John Rand's Considerations of Renewable Energy Resources for the South Pole and several field reports filed by Ed Cannon following survey trips to McMurdo and the South Pole. The following references have also been cited in the text.

Baring-Gould, E. I. (1996). Hybrid2: The Hybrid System Simulation Model Version 1.0 User Manual. 62 pp.; NREL Report No. TP-440-21272.

ENERCON GmbH, E-30 Product Brochure, www.wind.enron.com/index.html

Entegrity Wind Systems Inc, EW15 product brochure, www.entegritywind.com

Fuhrlander Wind Turbines, FL250 product brochure, www.lorax-energy.com

Northern Power Systems, NorthWind NW100/19 product brochure, www.northernpower.com/

Oy Windside, www.windside.com/

Vergnet WE Development, GEV 26/220 product brochure, www.vergnet.fr 


\section{Appendix A: Primer on Diesel Retrofit Opportunities}

The following background information provides an overview of the technology options available to retrofit a diesel power system. This is not meant to be all-inclusive and only covers internal changes to the power station. This does not address external efficiency measures that may also improve the performance of the power station.

The amount of wind at McMurdo and the South Pole Station discussed in this report is limited. It may be possible to install more wind at the South Pole, but this was not considered at this time.

There is a ranking of options for retooling a diesel power station, ranging from simply ensuring that the diesels installed at the plant are appropriately sized for the expected loads through the implementation of advanced renewable-based power systems (BaringGould 1997).

\section{Resize Diesel Generators}

The first opportunity to reduce the fuel consumption of a diesel power plant is to consider the size of engines that make up the plant. In many cases, diesel engines are oversized for the expected load because they are usually sized for the maximum possible load, not the normal or early morning load. Although this may seem like a safe procedure that lowers the risk of improper sizing, it may increase the fuel consumption of the plant. The impact of this will depend greatly on the size and age of the diesels under consideration because newer diesel engines have much better low-power efficiency.

\section{Apply Advanced Diesel Control}

Larger diesel plants often contain multiple diesel engines of various sizes. In these systems, it is more likely that the diesels will be the appropriate size; however, the diesels operating at any given point may not be the most efficient combination to cover that load. In these systems, controls can be placed on the diesel generators to enable automated dispatch and more efficient operation. Each genset is provided with controls for auto starting, synchronization, and load matching while a master control is used to coordinate diesel dispatching and load sharing. Automated systems have the additional advantage of detailed operational data collection and monitoring. Fuel savings depend on the current system design and dispatch strategy but tend to be cost effective in larger systems in which the current dispatch strategy is either inefficient or labor intensive. The use of advanced controls may add a level of technical sophistication that will only be appropriate in larger communities.

\section{Install Batteries and a Power Converter to Cover Low-Load Periods}

This approach is applicable in a single-diesel system if the community experiences periods of very light loading compared to the peak load. In these cases, the existing diesel is generally oversized for the low load period; thus it operates with poor efficiency. A retrofit battery bank and power converter, in which stored energy from the battery is used 
to power the converter and cover the load, allows the generator to be turned off during periods of light loading. The batteries are then recharged when the generator is operating at higher efficiency. This approach may also be used to expand the hours of service of a particular plant without greatly increasing the system operation costs. In multiple-diesel systems, the addition of batteries can preclude the need to start an additional generator that must run at low loading to cover power fluctuations over the rating of the primary generator. In either case, the generator recharges the batteries during other periods of the day. The decision of whether to install a converter/battery bank or a smaller diesel to cover these low-load periods is dependent on the ratio of low load to diesel size and should be considered carefully. The potential cost savings depend on the load profile and the sizes of the diesel generators. The size of the battery bank depends on the energy requirements of the low-load period. The size of the inverter depends on the magnitude of the load during the low-load period. Both the initial cost and the periodic replacement cost of the batteries must be weighed against the reduction in operation and maintenance expenses. In this system, the batteries cover the load in the early morning and then are recharged by the diesel later.

\section{Install Renewable Technology to Reduce Diesel Operation}

Retrofitting diesel power plants to incorporate renewable-based power generation allows for a potentially less expensive generation source to be used. In plants with many large

diesels, where there is always a demand for power, the renewable-based energy is used to offset power production by the generators, potentially to the point at which all generators can be shut off. The addition of renewable-based power may also reduce the number of generators operating at any given time, thus reducing the diesel maintenance requirements. Because system dynamics and power stability are of primary concern, the power system must be designed to ensure that the inclusion of the renewable-based generation does not degrade overall power quality.

This approach can be very cost effective but is capital intensive because of the cost of the new generation and system controls. The potential cost savings depend on the renewable resource, component maintenance costs, equipment capital costs, and the fuel price. Based on current prices, photovoltaics (PV) is usually not cost effective in large systems when compared to the marginal cost of diesel fuel. Plants with access to reasonable wind resources, generally greater than Class $1(5.9 \mathrm{~m} / \mathrm{s}$ annual average $)$, could significantly reduce operating costs by the inclusion of some amount of wind generation (Allderdice and Rogers 2000; Baring-Gould et. al. 2000, 2001; Jimenez and Lawand 2000; Jimenez and Olson 1998).

The next sections describe considerations and configurations of wind/diesel power stations.

\section{Wind/Diesel Applications}

Wind/diesel power systems can vary from simple designs in which wind turbines are connected directly to the diesel grid with a minimum of additional features to more complex systems. Two overlapping concepts depict the system design and required 
components: the amount of energy that is expected from the renewable sources (system penetration) and the decision to use a storage device to remedy system energy

fluctuations. Given today's technology, these issues are usually selected by the system designers as a starting point for system design (Ackermann et. al. 2005; Baring-Gould et. al. 2003; Hunter and Elliot 1994). These concepts are described in the following section.

\section{Renewable Penetration}

When incorporating renewable-based technologies into large power systems, the amount of energy that will be obtained from the renewable sources must be determined because this will dictate which components will be used. Steve Drouilhet developed the following classification and definitions of system penetration that characterize the levels of system complexity:

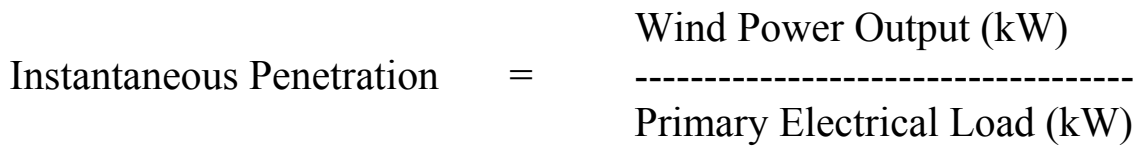

and

$$
\begin{aligned}
& \text { Average Penetration } \quad=\quad \text { Wind Turbine Energy Output }(\mathrm{kWh}) \\
& \text { Primary Electrical Load (kWh) }
\end{aligned}
$$

The difference in these equations is the units. Instantaneous penetration is in terms of power; thus, it is the ratio of how much power is being produced by the renewable resources at any specific instant. The average penetration is in terms of energy; it includes a time domain and is thus measured over days, months, or even years. In some sense, average penetration is in the domain of the economist and instantaneous penetration falls in the realm of the engineer. Drouilhet also proposed a three-level classification system based on system penetration that separates systems along power and system control needs (Table A.1). There are no references that can be attributed to Steve Drouilhet on this topic; however, the methodologies are discussed further in Ackermann 2005 and Baring-Gould et. al. 2003. 


\section{Table A.1: Penetration Class of Wind-Diesel Systems (Proposed by Steve Drouilhet)}

\begin{tabular}{|c|c|c|c|}
\hline \multirow[b]{2}{*}{$\begin{array}{c}\text { PENETRATION } \\
\text { CLASS }\end{array}$} & \multirow[b]{2}{*}{ OPERATING CHARACTERISTICS } & \multicolumn{2}{|c|}{ PENETRATION } \\
\hline & & $\begin{array}{c}\text { PEAK } \\
\text { INSTANTANEOUS }\end{array}$ & $\begin{array}{c}\text { ANNUAL } \\
\text { AVERAGE }\end{array}$ \\
\hline LOW & $\begin{array}{l}\text { - Diesel runs full-time } \\
\text { - Wind power reduces net load on } \\
\text { diesel } \\
\text { - All wind energy goes to primary } \\
\text { load } \\
\text { - No supervisory control system }\end{array}$ & $<50 \%$ & $<20 \%$ \\
\hline MEDIUM & $\begin{array}{l}\text { - Diesel runs full-time } \\
\text { - At high wind power levels, } \\
\text { secondary loads dispatched to } \\
\text { ensure sufficient diesel loading or } \\
\text { wind generation is curtailed } \\
\text { - Requires relatively simple control } \\
\text { system }\end{array}$ & $50 \%-100 \%$ & $20 \%-50 \%$ \\
\hline $\mathrm{HIGH}$ & $\begin{array}{l}\text { Diesels may be shut down during } \\
\text { high wind availability } \\
\text { - } \begin{array}{l}\text { Auxiliary components required to } \\
\text { regulate voltage and frequency }\end{array} \\
\text { - } \begin{array}{l}\text { Requires sophisticated control } \\
\text { system }\end{array}\end{array}$ & $100 \%-400 \%$ & $50 \%-150 \%$ \\
\hline
\end{tabular}

\section{Wind/Diesel Power System Configurations}

Low-Penetration Systems: Many low-penetration systems have been installed worldwide. These vary from small to relatively large isolated grids, such as those found on several Greek islands. In fact, some large grids, such as those found in certain areas of the United States and Europe, reach a wind power penetration that would classify them in the same category as low-penetration systems. Basically, low-penetration systems are those in which the renewable generation source is just another source, requiring no special arrangements. The control technology required at this level of generation is trivial, especially given the control, flexibility, and speed of modern diesel and wind systems. In many systems, no form of automated control is required - the wind turbines act under their commercial controllers and an operator monitors all system functions. Because the diesel engines are designed to allow for rapid fluctuations in power requirements from the load, the addition of wind has very limited impact, if any, on the 
ability of the diesel control to provide the remaining difference. Issues of spinning reserve, a term used to represent the availability of instantaneous system capacity to cover rapid changes in system load or energy production, are addressed by the allowable capacity of the diesel engines, which in many cases can run at $125 \%$ rated power for short periods of time with no adverse impact on the diesel or generator. A generic schematic of a low-penetration system is shown in Figure A.1 (Lundsager and Madsen 1995 and Lundsager et. al. 2001).

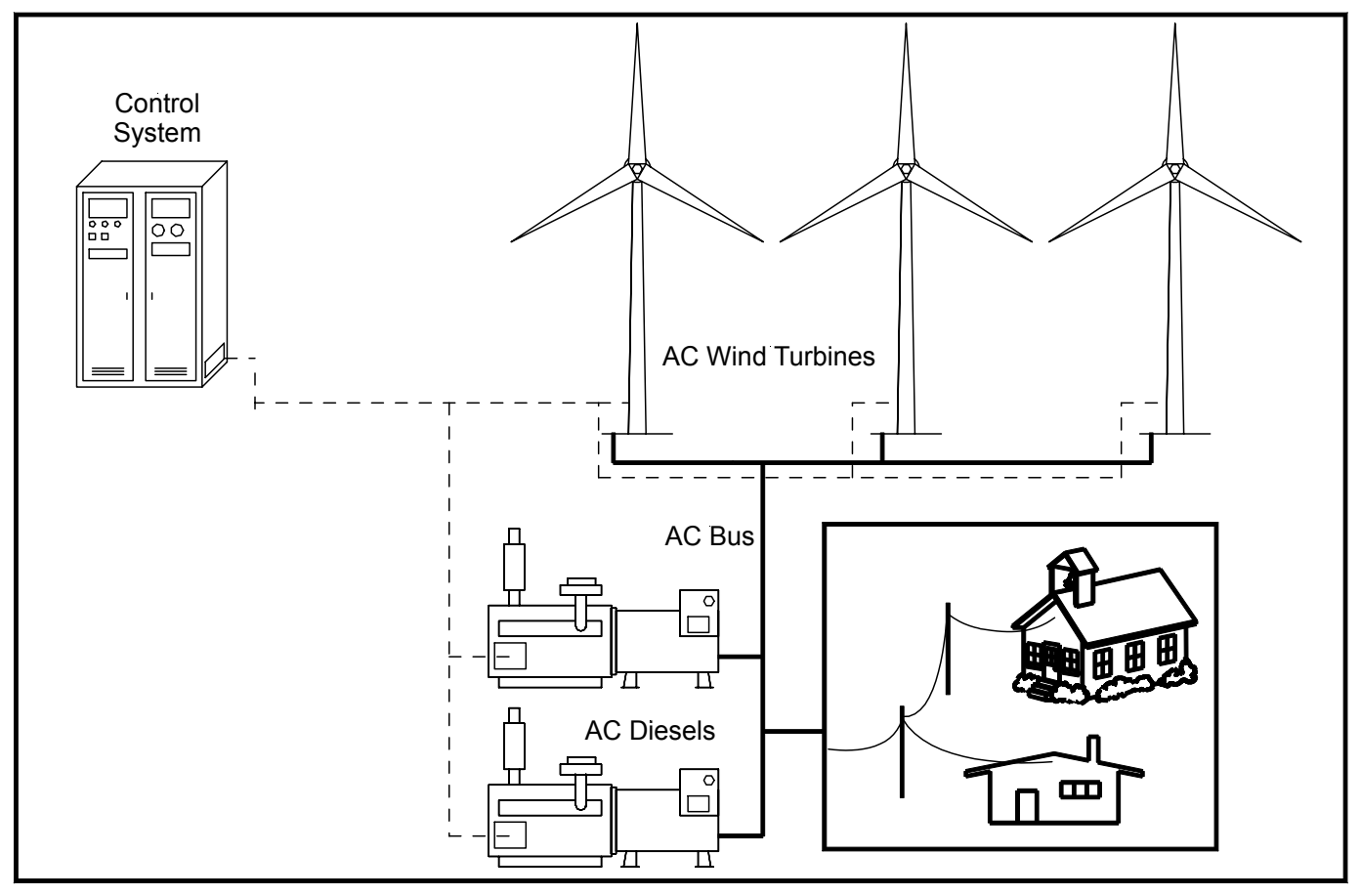

Figure A.1: Schematic of low-penetration wind/diesel hybrid 
Medium-Penetration Systems: Systems with larger ratios of renewable energy contribution fall into this category. Allowing power penetrations of up to $50 \%$ will allow any under-loaded diesel generators in multiple diesel plants to be shut off or to be switched to a smaller unit for production. This, in turn, will reduce plant diesel consumption and reduce diesel engine operation. However, this may also open the power system to potential shortfalls, assuming the loss of one or more of the wind generators or diesel engines. In addition, with a large penetration of energy being produced by the variable renewable source, it will become harder for the operating diesel units to tightly regulate system voltage and maintain an adequate power balance. There are options to ensure that the high-power-quality requirements of the power system are maintained, even with half of the energy provided by renewable sources. Some of the options include power reduction capabilities within the wind turbine controller, the inclusion of a secondary load to ensure that no more than a specified amount of energy will be generated by the wind, installation of capacitor banks to correct power factor, or even the use of advanced power electronics to allow real-time power specification.

Spinning reserve on medium-penetration power systems requires experience in regard to proper power levels and system commitments but is not considered technically complex. Such spinning reserve questions should be handled on a case-by-case basis but can be partially solved by using options, including the use of advanced diesel controls, the installation of a modern diesel engine with fast start and low-loading capabilities, controlled load shedding or reduction, power forecasting, and proper system oversight. Combined with the use of variable-speed or advanced-power conditioning available on many modern wind turbines, the control requirements of medium-penetration systems are quite simple. The ability to provide high power quality in medium-penetration power systems has been demonstrated for years in a number of highly important locations. The most notable examples are the military diesel plants on San Clemente Island and Ascension Island and the power system in Kotzebue, Alaska. All of these systems have experienced power penetration at or above these guidelines set for medium-penetration systems (McKenna and Olsen 1999).

High-Penetration Systems: Although this technology has been demonstrated on a commercial basis, high-penetration wind-diesel power stations require a much higher level of system integration, technology complexity, and advanced control. The principle of operation of high-penetration systems is that the required equipment is installed in addition to the wind turbine so that the diesel can be shut off completely when there is an abundance of renewable-power production. Any instantaneous power production over the required electrical load, an instantaneous penetration over $100 \%$, is supplied to a variety of controllable secondary loads. In these systems, synchronous condensers, load banks, dispatchable loads (and possibly storage in the form of batteries or flywheel systems), power converters, and advanced system controls are used to ensure power quality and system integrity. Spinning reserve is created through the use of short-term storage or the maintenance of a consistent oversupply of renewable energy. Although these systems are demonstrated commercially, they are not yet considered a mature technology and have not been demonstrated on systems larger than approximately $200-\mathrm{kW}$ average load. A 
generic schematic of a high penetration with storage is shown in Figure A.2 (Drouilhet 2001).

Systems Storage: Until recently, it was assumed that wind-diesel systems without storage were theoretical, possibly born out of short-term testing in test-stand-based power systems. This is no longer the case. Commercially operating short-term and no storage systems have been installed in recent years, demonstrating that both technology choices are viable.

In systems incorporating storage, the storage is used to cover short-term fluctuations in renewable power. The premise of this system design is that a large penetration of renewables is used (up to $300 \%$ of the average power requirements). When the renewable-based generators supply more power than is needed by the load, the engine generators can be shut down. During lulls in the renewable power generation, discharging the battery bank or other storage device supplies any needed power. If the lulls are prolonged or the storage becomes discharged, an engine generator is started and takes over supplying the load. Studies have indicated that most lulls in power from the wind are of limited duration, and using storage to cover these short time periods can lead to significant reductions in the consumption of fuel, generator operational hours, and reduced generator starts.

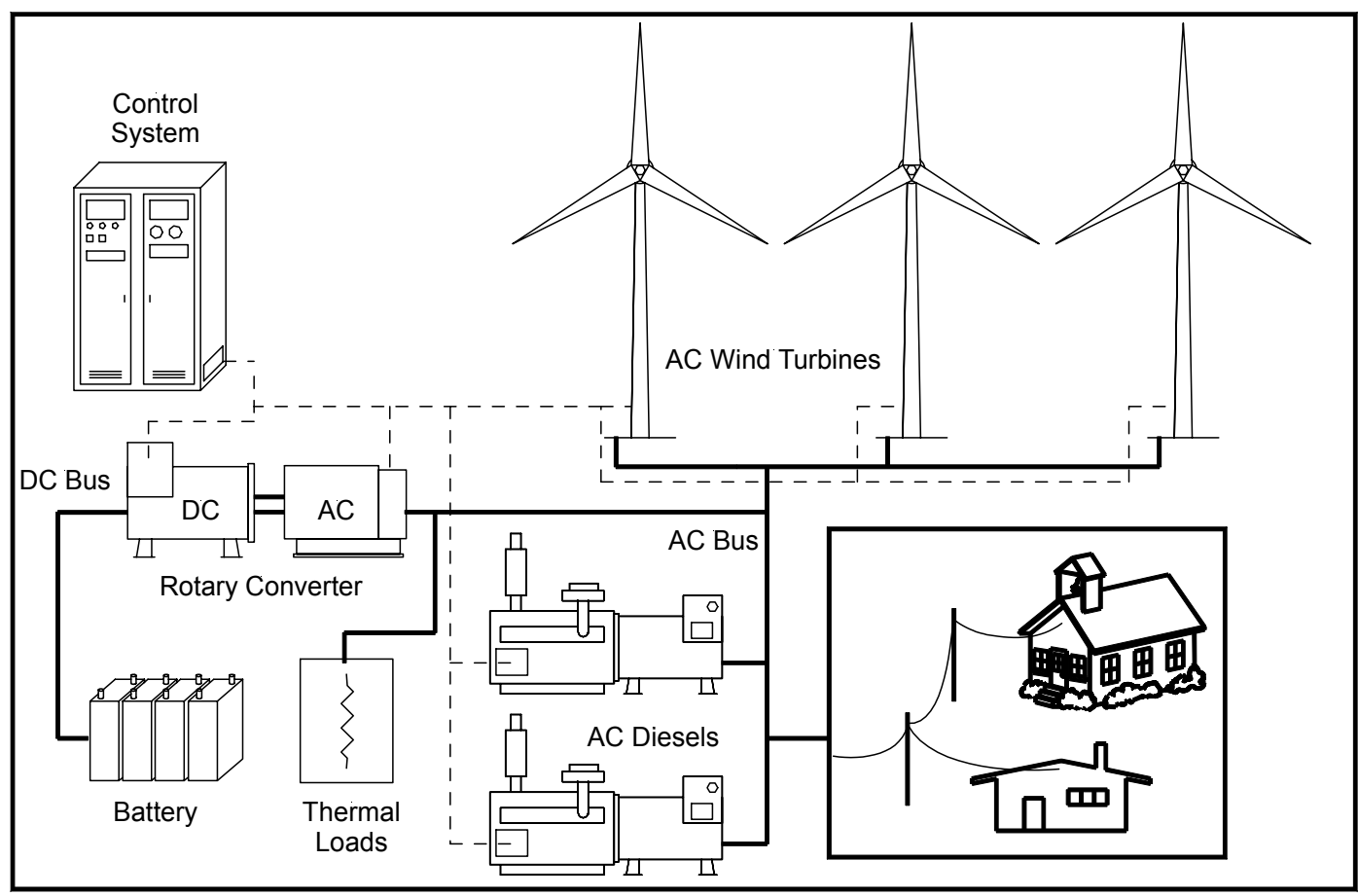

Figure A.2: Schematic of high-penetration wind/diesel power system using a rotary power converter 
In large power systems, the installation of a battery bank to cover shortfalls in renewable production may not be feasible, mainly because of cost. However, without storage it is very difficult to control the stability of a conventional power grid with large quantities of renewable power - thus the challenge of hybrid systems without storage. This configuration is based on the AC bus and does not use batteries to provide grid stabilization. The basic premise of these systems is that the installed capacity of the renewable technology is much larger than the load. When the renewable devices are operating and producing more energy than is needed by the load by some margin, usually between $125 \%$ and $150 \%$, the dispatchable generators can be turned off. External control devices, such as dispatchable secondary loads, fast-acting dump loads, synchronous condensers, and advanced diesel control are used to maintain system stability and control. If the renewable energy dips below a specified threshold, a generator is started to ensure power security or some of the dispensable loads can be disconnected to increase the systems headroom. This type of system produces a large amount of extra energy that must be used if the project is to be economical. This is completed with a large thermal storage tank that acts as a buffer for the electrical load, allowing the smoothing of the variable wind energy and dispatching a diesel generator when there is not enough energy to cover the loads or if the thermal storage tank temperature drops below a specified limit. The control system and hardware requirements are less complex than a system using battery storage; however, the facility must have a large and expensive heating requirement to cover the cost of the additional infrastructure, which is the case for Antarctica.

All high-penetration systems, with and without storage, have been installed in northern climates where the extra energy can be used for heating buildings or water, displacing other fuels. In these systems, it may be wise to install uninterruptible power supplies (UPSs) on critical loads. Although only a limited number of systems have been installed, the concept is economically attractive and can drastically reduce fuel consumption in remote communities (Beyer et. al. 1987; Shirazi and Drouilhet 1997). 


\section{Appendix References}

Ackermann, T. (2005). Wind Power in Power Systems. West Sussex, England: John Wiley and Sons.

Allderdice, A.; Rogers, J. H. (2000). Renewable Energy for Microenterprise (Booklet). 80 pp.; NREL Report No. BK-500-26188.

Baring-Gould, E.I.; Barley, C.D.; Drouilhet, S.; Flowers, L.; Jimenez T.; Lilienthal, P.; Weingart, J. (1997). Diesel Plant Retrofitting Options to Enhance Decentralized Electricity Supply in Indonesia. Proceedings of the 1997 AWEA Conference, Austin, TX. June 1997.

Baring-Gould, E.I.; Flowers, L.; Jimenez, A. C.; Lilienthal, P. (2000). Opportunities for Regional Rural Electrification Using Hybrid Power Systems. Proceedings of the 2000 Wind Energy for the $21^{\text {st }}$ Century Technical Symposium, Kassel, Germany.

Baring-Gould, E.I.; Flowers, L.; Lundsager, P.; Mott, L.; Shirazi, M.; Zimmermann, J. (2003). World Status of Wind Diesel Applications. Proceedings of the 2003 AWEA Conference, Austin, TX.

Baring-Gould, E.I.; Newcomb, C.; Corbus, D.; Kalidas, R. (2001). Field Performance of Hybrid Power Systems. 13 pp.; NREL Report No. CP-500-30566.

Beyer, H.G.; Gabler, H.; Gerdes, G.J.; Heinemann, D.; Luther, J.; Schumacher-Gröhn, J.; Steinberger-Willms, R. (1987). Wind/Solar Hybrid Electricity Generation for Stand Alone Systems with Battery and Hydrogen Storage. Proc. 5th Int. Conf. on Energy Options - The Role of Alternatives in the World Energy Scene, Reading, 7-9 April $1987,132-135$.

Drouilhet, S. (2001). Preparing an Existing Diesel Power Plant for a Wind Hybrid Retrofit: Lessons Learned in the Wales, Alaska, Wind-Diesel Hybrid Power Project. 13 pp.; NREL Report No. CP-500-30586.

Hunter, R.; Elliot, G. (Eds). (1994). Wind-Diesel Systems. Cambridge, UK: Cambridge University Press.

Jimenez, A. C.; Lawand, T. (2000). Renewable Energy for Rural Schools (Booklet). 64 pp.; NREL Report No. BK-500-26222.

Jimenez, A. C.; Olson, K. (1998). Renewable Energy for Rural Health Clinics. 52 pp.; NREL Report No. BK-500-25233.

Lundsager, P.; Bindner, H.; Clausen, Niels-Erik; Frandsen, Sten; Hansen, Lars Henrik; Hansenet, Jens Carsten. (2001). Isolated Systems with Wind Power-Main Report. Risø-R-1256 (EN). Riso National Laboratory.

Lundsager, P.; Madsen, B.T. (1995). Wind Diesel and Stand Alone Wind Power Systems. Final Report May 1995, BTM Consult and Darup Associates ApS. 
McKenna, E.; Olsen, T. (1999). Performance and Economics of a Wind-Diesel Hybrid Energy System: Naval Air Landing Field, San Clemente Island, California. 109 pp.; NREL Report No. SR-500-24663.

Shirazi, M.; Drouilhet, S. (1997). Analysis of the Performance Benefits of Short-Term Energy Storage in Wind-Diesel Hybrid Power Systems. 13 pp.; NREL Report No. CP440-22108. 


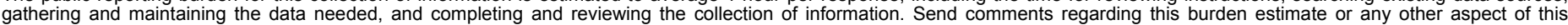

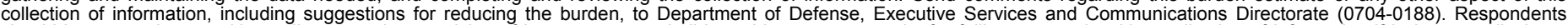

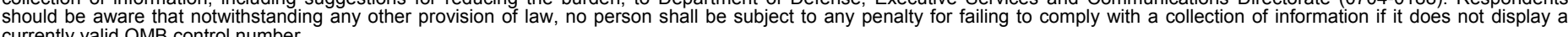

PLEASE DO NOT RETURN YOUR FORM TO THE ABOVE ORGANIZATION.

\section{REPORT DATE (DD-MM-YYYY) May 2005 \\ 2. REPORT TYPE \\ Technical Report}

\section{TITLE AND SUBTITLE}

Analysis of the Use of Wind Energy to Supplement the Power Needs at McMurdo Station and Amundsen-Scott South Pole Station, Antarctica
3. DATES COVERED (From - To) 5a. CONTRACT NUMBER

DE-AC36-99-G010337

5c. PROGRAM ELEMENT NUMBER

5d. PROJECT NUMBER

NREL/TP-500-37504

\section{5e. TASK NUMBER}

WER5 7202

5f. WORK UNIT NUMBER
7. PERFORMING ORGANIZATION NAME(S) AND ADDRESS(ES)

National Renewable Energy Laboratory

1617 Cole Blvd.

Golden, CO 80401-3393
9. SPONSORING/MONITORING AGENCY NAME(S) AND ADDRESS(ES)

\section{PERFORMING ORGANIZATION REPORT NUMBER}

NREL/TP-500-37504

10. SPONSOR/MONITOR'S ACRONYM(S) NREL

11. SPONSORING/MONITORING AGENCY REPORT NUMBER

12. DISTRIBUTION AVAILABILITY STATEMENT

National Technical Information Service

U.S. Department of Commerce

5285 Port Royal Road

Springfield, VA 22161

\section{SUPPLEMENTARY NOTES}

14. ABSTRACT (Maximum 200 Words)

This report summarizes an analysis of the inclusion of wind-driven power generation technology into the existing diesel power plants at two U.S. Antarctic research stations, McMurdo and Amundsen-Scott South Pole Station. Staff at the U.S. Department of Energy's National Renewable Energy Laboratory (NREL) conducted the analysis.

Raytheon Polar Services, which currently holds the private sector support contract for the two research stations, was a major contributor to this report. To conduct the analysis, available data were obtained on the wind resources, power plant conditions, load, and component cost. Whenever possible, we validated the information. We then used NREL's Hybrid2 power system modeling software to analyze the potential and cost of using wind turbine generators at the two aforementioned facilities. Unfortunately, the power systems and energy allocations at McMurdo and South Pole Station are being redeveloped, so it is not possible to validate future fuel use. This report is an initial assessment of the potential use of wind energy and should be followed by further, more detailed analysis if this option is to be considered further.

15. SUBJECT TERMS

wind energy; wind turbine; McMurdo Station; Amundsen-Scott South Pole Station; diesel; Antarctica; Hybrid2; power systems

16. SECURITY CLASSIFICATION OF:

\begin{tabular}{|l|l|l}
\hline a. REPORT & b. ABSTRACT \\
Unclassified & Unclassified & UnIS PAGE \\
& & \\
&
\end{tabular}

\section{9a. NAME OF RESPONSIBLE PERSON}

19b. TELEPHONE NUMBER (Include area code) 